\title{
Active and passive immunization strategies based on the SDPM1 peptide demonstrate pre-clinical efficacy in the APPswePSEN1dE9 mouse model for Alzheimer's disease
}

\author{
Marybeth Camboni ${ }^{1}{ }^{,}$, Chiou-Miin Wang ${ }^{1,{ }^{*}}$, Carlos Miranda ${ }^{1}$, Jung Hae Yoon ${ }^{1}$, Rui Xu ${ }^{1}$, \\ Deborah Zygmunt ${ }^{1}$, Brian K. Kaspar ${ }^{1,2,4}$, and Paul T. Martin ${ }^{1,2,3, \#}$ \\ ${ }^{1}$ Center for Gene Therapy, The Research Institute at Nationwide Children's Hospital, The Ohio \\ State University \\ ${ }^{2}$ Department of Pediatrics, The Ohio State University \\ ${ }^{3}$ Department of Physiology and Cell Biology, The Ohio State University \\ ${ }^{4}$ Department of Neuroscience, The Ohio State University
}

\section{Abstract}

Recent clinical and pre-clinical studies suggest that both active and passive immunization strategies targeting $A \beta$ amyloid may have clinical benefit in Alzheimer's disease. Here, we demonstrate that vaccination of APPswePSEN1dE9 mice with SDPM1, an engineered non-native $\mathrm{A} \beta$ amyloid-specific binding peptide, lowers brain $\mathrm{A} \beta$ amyloid plaque burden and brain $A \beta 1-40$ and $A \beta 1-42$ peptide levels, improves cognitive learning and memory in Morris Water maze tests and increases the expression of synaptic brain proteins. This was the case in young mice immunized prior to development of significant brain amyloid burden, and in older mice, where brain amyloid was already present. Active immunization was optimized using ALUM as an adjuvant to stimulate production of anti-SDPM1 and anti-A $\beta$ amyloid antibodies. Intracerebral injection of P4D6, an SDPM1 peptide-mimotope antibody, also lowered brain amyloid plaque burden in APPswePSEN1dE9 mice. Additionally, P4D6 inhibited A $\beta$ amyloid-mediated toxicity in cultured neuronal cells. The protein sequence of the variable domain within the P4D6 heavy chain was found to mimic a multimer of the SDPM1 peptide motif. These data demonstrate the efficacy of active and passive vaccine strategies to target specific $A \beta$ amyloid oligomers using an engineered peptide-mimotope strategy.

\section{Keywords}

Alzheimer's disease; vaccine; peptide mimotope; amyloid; neurodegeneration; learning; memory; synaptophysin; PSD95; synapse

(C) 2013 Elsevier Inc. All rights reserved.

\#Author for Correspondence: Center for Gene Therapy, The Research Institute at Nationwide Children's Hospital, 700 Children's Drive, Columbus, OH 43205, Phone:(614) 722-4072, FAX:(614) 722-5893, Paul.Martin@ nationwidechildrens.org.

These authors contributed equally to this work

CONFLICT OF INTEREST

PTM is the inventor of SDPM1 peptide and P4D6, an SDPM1 peptide-mimotope antibody, both of which are protected by US patents US7745569 and US8394375. None of the other authors have any conflicts to disclose related to the publication of this work.

Publisher's Disclaimer: This is a PDF file of an unedited manuscript that has been accepted for publication. As a service to our customers we are providing this early version of the manuscript. The manuscript will undergo copyediting, typesetting, and review of the resulting proof before it is published in its final citable form. Please note that during the production process errors may be discovered which could affect the content, and all legal disclaimers that apply to the journal pertain. 


\section{INTRODUCTION}

Alzheimer's disease (AD) is the most common form of dementia in the elderly(Bachman et al., 1992). $\mathrm{AD}$ is triggered, at least in part, by the formation of $\mathrm{A} \beta$ amyloid arising from generation of A $\beta 1-40$ and A $\beta 1-42$ peptides(Hardy and Higgins, 1992; Selkoe, 2001a; Selkoe, 2001b), and low molecular weight $A \beta$ peptide oligomers impact synaptic function, synaptic structure, cognition and neuronal cell death(Barghorn et al., 2005; Cleary et al., 2005; Hsieh et al., 2006; Kim et al., 2001; Lambert et al., 1998; Lesne et al., 2006; Shankar et al., 2007; Shankar et al., 2008; Walsh et al., 2002; Wei et al., 2010). Additional pathologic findings in $\mathrm{AD}$ brain include hyperphosphorylation of the microtubule binding protein tau, formation of neurofibrillary tangles, synaptic dysfunction, loss of synaptic density and neurodegeneration(DeKosky and Scheff, 1990; Lace et al., 2007; Marcello et al., 2012; Masliah et al., 1991; Pham et al., 2010; Selkoe, 2001a; Terry, 1996; Terry et al., 1991). Pathological findings, in turn, correlate with alterations in cognitive functions, such as learning and memory(DeKosky and Scheff, 1990; Masliah et al., 1991; Nelson et al., 2012; Terry et al., 1991). Bi-transgenic AD mouse models that overexpress early onset mutations in APP and PSEN1 mutants (APP/PS) in neurons reiterate some, but not all, of these important aspects of $\mathrm{AD}$ (Borchelt et al., 1997; Morrissette et al., 2009).

Both active and passive vaccine strategies based on immunization with the $A \beta$ peptide or its variants have been shown, in some cases, to have clinically meaningful benefits in Alzheimer's disease patients(Delrieu et al., 2012). Schenck and colleagues first showed that immunization with $A \beta 1-42$ peptide could lower brain $A \beta$ amyloid plaque burden in an $A D$ mouse model(Schenk et al., 1999). This led to a phase 1 and phase2a AD clinical trials by ELAN/Wyeth (AN1792). This trial was interrupted in phase2a due to the finding of meningoencephalitis with $\mathrm{T}$ cell infiltrates in a subset of the vaccinated patients(Orgogozo et al., 2003; Pride et al., 2008). Despite the interruption of the trial, some patients did develop serum antibody titers to the $\mathrm{A} \beta$ peptide and showed cognitive improvement(Ghochikyan et al., 2006; Gilman et al., 2005; Hock et al., 2003). Analysis of patients in the AN1792 trial that have come to autopsy has documented reductions in brain $A \beta$ amyloid plaque burden(Nicoll et al., 2006). A host of additional active vaccine trials are currently ongoing that focus on utilizing shorter $\mathrm{A} \beta$ peptides that are devoid of $\mathrm{T}$ cell activation epitopes(Cribbs, 2010; Delrieu et al., 2012; Lemere, 2009; Schneeberger et al., 2009; Tabira, 2010). Passive vaccine therapies utilizing antibodies that target different regions of the $\mathrm{A} \beta 1-42$ peptide or $\mathrm{A} \beta$ oligomers are also currently being tested (Bard et al., 2003; Carty et al., 2006; Delrieu et al., 2012; DeMattos et al., 2001; Laskowitz and Kolls, 2010; Levites et al., 2006a; Levites et al., 2006b; Ostrowitzki et al., 2012; Panza et al., 2012; Pride et al., 2008; Wilcock et al., 2003; Yamada et al., 2009).

Using a phage display method, we have identified several cysteine-bounded 20 amino acid peptides that can bind specifically to low molecular weight oligomers of $A \beta 1-40$ and $A \beta 1-42$ amyloid and can block subsequent A $\beta$ oligomerization(Kang et al., 2003; Wang et al., 2010). One of these peptides is SDPM1. Some antibodies that bind SDPM1 can display peptidemimotope activity, having the same $A \beta$ amyloid binding and blocking activities as SDPM1 itself has(Wang et al., 2010). We have previously shown that immunization of APP/PS mice with SDPM1 to generate such peptide-mimotope antibodies lowers brain A $\beta$ amyloid plaque burden and improves learning and memory without causing increased brain inflammation(Wang et al., 2010). While effective, this previous approach was not easily translatable to the clinic. Here we have altered our approach to immunize APP/PS mice with SDPM1 bound to ALUM, a commonly used adjuvant in clinical vaccines(Schijns and Lavelle, 2011). In addition, we assess passive vaccination with P4D6, an SDPM1-peptide mimotope antibody(Wang et al., 2010), and report its sequence. 


\section{MATERIALS AND METHODS}

\section{Animals}

APPswePSEN1dE9 transgenic mice (JAX strain B6C3-Tg(APPswePSEN1dE9)85Dbo/ Mmjax, stock\# 004462) and non-transgenic littermate controls were obtained from Jackson Laboratories (Bar Harbor, ME). Mice were bred and genotyped as previously described(Borchelt et al., 1997). All experiments were done with approval of the Institutional Animal Care and Use Committee at Nationwide Children's Hospital. Transgenes were maintained as heterozygous alleles for all experiments. Mice had access to food and water ad libitum and were kept on a 12:12hr light dark cycle. All animals were housed in a clean barrier facility and were housed individually prior to Morris Water Maze and Open Field assessments. For each measure in each experimental group, half of the animals analyzed were male and half of the animals analyzed were female.

\section{Vaccination protocols}

SDPM1-4E peptide (EEEEAECDWGKGGRWRLWPGASGKTEACGP) was synthesized and purified to $>95 \%$ purity by AmbioPharm (North Augusta, SC). Peptide purity was analyzed by HPLC and mass spectrometry. SDPM1-4E was bound to Alhydrogel $\left(\mathrm{Al}(\mathrm{OH})_{3}\right.$,) (Accurate Chemical and Scientific Corp.; Westbury, NY from Brenntag; Fredrickssund, Denmark). $1 \mathrm{~mL} 2 \%$ Alhydrogel (hereby called ALUM, formulated with $10.3 \mathrm{mg} / \mathrm{ml}$ aluminum) was washed 3 times with $10 \mathrm{~mL}$ sterile phospho-buffered saline (PBS, $\mathrm{pH}$ 7.4) prior to peptide addition.

For vaccine optimization experiments, $25 \mu \mathrm{g}, 50 \mu \mathrm{g}$ or $100 \mu \mathrm{g}$ of SDPM1-4E was added to $25 \mu \mathrm{g}$ of ALUM in 100 $\mu$ L PBS. Total amounts of each solution made were scaled according to the number of injections to be performed. The solution was mixed by gentle rocking overnight at $4^{\circ} \mathrm{C}$. After overnight conjugation, centrifugation of the ALUM-SDPM1-4Econjugate showed no unbound peptide remaining in the supernatant, as measured by

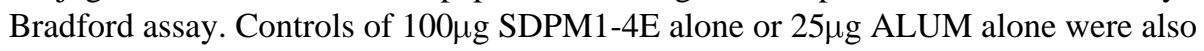
prepared. Mice were bled one day prior to first immunization to assess baseline serum antibody titers. Adult wild type mice $(\mathrm{C} 57 \mathrm{Bl} / 6)$ were then injected subcutaneously using a $0.3 \mathrm{~mL}$ insulin syringe with $100 \mu \mathrm{L}$ vaccine solution in the dorsal neck area. Mice were injected once every two weeks for a total of five injections. Relative to the time of the first injection, mice were bled at 0, 6, 12 and 24 weeks and serum antibody titers analyzed.

For AD vaccine therapy experiments, APPswePSEN1dE9 (APP/PS) mice were injected using one of two paradigms. In the first paradigm, YOUNG (6 month-old) APP/PS mice were injected subcutaneously once every two weeks for a total of four injections with $100 \mu \mathrm{g}$ SDPM1-4E peptide conjugated to 25 $\mu \mathrm{g}$ ALUM. Control mice were similarly injected with $25 \mu \mathrm{g}$ ALUM or PBS alone. In the second paradigm, OLD (12 month-old) APP/PS mice were injected subcutaneously once every two weeks for a total of four injections with $100 \mu \mathrm{g}$ SDPM1-4E peptide conjugated to 25 $\mu$ g ALUM (again with ALUM or PBS as controls). Mice may have varied by as much as 3 weeks in age below the 6- or 12-month time point for YOUNG or OLD mice, respectively, at the beginning of the experiment, but in each instance analysis was done after a treatment period of exactly 6 months. Mice were analyzed for learning and memory and bled to assess serum antibody titers at 24 weeks after the first immunization. They were then euthanized and their brains harvested for further analysis.

\section{Serum ELISA assays of SDPM1 and A $\beta$ amyloid antibody titers}

$100-200 \mu \mathrm{L}$ of blood was isolated from the facial vein and allowed to clot for 30 minutes at $37^{\circ} \mathrm{C}$ in non-heparinized tubes, after which samples were centrifuged at $3000 \mathrm{~g}$ for 5 minutes to collect serum. SDPM1-specific antibody titers and A $\beta 1-42$ amyloid-specific antibody 
titers were assayed on 96-well ELISA plates (NUNC \#449824) as previously described (Wang et al., 2010). Addition of secondary antibody alone to SDPM1- or A $\beta 1-42-$ immobilized wells yielded a background signal that never exceeded $10 \%$ of the maximal primary antibody signal. Signals from SDPM2 background were subtracted from SDPM1positive signals to generate anti-SDPM1 antibody titers. To determine antibody subtypes, the protocol was repeated, only goat anti-mouse antibodies specific for mouse IgM, IgG1, IgG2a, IgG2b, IgG3 or IgA (Southern Biotech: 5300-05) were used.

\section{Immunohistochemistry and immunofluorescence microscopy}

Mice were exsanguinated by perfusion in PBS under anesthetic with ketamine and xylazine. Mouse brains were removed and bisected at the midsagittal plane. Half of the brain was snap frozen in liquid nitrogen to use in biochemical experiments. The other half was fixed in $4 \%$ paraformaldehyde overnight. Brains were then washed in PBS and fixative quenched in $0.1 \mathrm{M}$ glycine, sunk in 10-30\% sucrose gradient overnight, mounted in OCT (Optimal Cutting Temperature) and frozen in dry ice-cooled isopentane. $10 \mu \mathrm{m}$ sagittal sections of brain were cut on a cryostat. Slides were stained in Thioflavin S for 5 minutes, then sequentially washed in 70\% ethanol and doubly distilled (dd) $\mathrm{H}_{2} \mathrm{O}$. For $\mathrm{A} \beta 1-42$ staining, slides were blocked in PBS with $10 \%$ goat serum, incubated with biotinylated mouse antiA $31-42$ (6E10) antibody, washed in PBS and incubated with Cy3-conjugated streptavidin. A similar approach was used to stain for astrocytes (anti-GFAP, Zymed, 1800063), microglia (anti-Iba1, Wako 019-19741), activated microglia (anti-CD68, AbD Serotec MCA1957GA), T cells (anti-CD4, BDPharmingen, 550278; anti-CD8, BDPharmingen, 550281) or B cells (anti-B220, BDPharmingen 550286), only Cy3-conjugated goat anti-rabbit (for Iba1, GFAP) or goat anti-rat (for CD68, B220, CD4, CD8) secondary antibodies were used.

Synaptophysin (Ab9272, Upstate Biotechnology, Lake Placid, NY) staining was done to identify relative synaptic density in the frontal region of the cortex and in the outer molecular layer (ML) of the hippocampus. All fluorophore-, biotin-, or HRP-conjugated secondary antibodies or streptavidin were purchased from Jackson ImmunoResearch (Seattle, WA).

\section{Image analysis}

$10 \mu \mathrm{m}$ serial sagittal sections were collected beginning $720 \mu \mathrm{m}$ laterally from the midplane by cryostat sectioning and stained with Thioflavin $S$ to visualize fibrillar dense core $A \beta$ amyloid plaques. 8-12 sections, each spaced $80 \mu \mathrm{m}$ apart, were used to image amyloid plaque burden, plaque number and plaque size in the hippocampus and the cortex. For cortex, equivalent numbers of images were averaged from frontal, medial and posterior cortical regions. Stained images were recorded using a Zeiss Axiophot epifluorescence microscope and Zeiss AxioVision LE 4.1 software. 10x images were recorded to analyze amyloid plaque burden, while 20x images were used to record cells stained for GFAP, Iba1, or CD68. Synaptic density was indirectly assessed by immunostaining with synaptophysin in the molecular layer of the hippocampus and in the frontal neocortex. For comparisons of staining intensity, all images were collected using identical exposure settings using the same illumination intensity and filters. Images were then converted to a greyscale TIFF format and analyzed using NIH Image J (1.42) software as previously described(Wang et al., 2010). Sections were blinded with respected to the investigator prior to analysis, and multiple investigators participated in the quantification of each measure, with similar results. Each datum reflects summation of a $708 \times 528 \mu \mathrm{m}$ image for quantification of $\mathrm{A} \beta$ plaque burden, number and size, and a $354 \times 265 \mu \mathrm{m}$ image for quantification of GFAP-, Iba1-or CD68positive cell density and synaptophysin staining intensity. 8-12 sections per animal were used to calculate the number of cells immunostained with antibodies to GFAP, Iba1 and CD68 and to quantify synaptophysin immunostaining. 


\section{Quantification of brain $A \beta 1-40$ and $A \beta 1-42$ peptides}

Unfixed snap-frozen brain was weighed and solubilized in 2\% SDS denaturation buffer as previously described(Wang et al., 2010). After precipitation of insoluble material at $16000 \mathrm{~g}$ for 20 minutes, extracted brain proteins (SDS-soluble) were assayed using ELISA kits for A $\beta 1-40$ (Invitrogen, KHB3482) and A $\beta 1-42$ peptide (Invitrogen, KHB3442) following the manufacturer's instructions. Precipitated (SDS-insoluble) pellets were extracted in formic acid, as before(Wang et al., 2010), centrifuged at $100000 \mathrm{~g}$, and supernatant neutralized in $1 \mathrm{M}$ Tris-base $/ 0.5 \mathrm{M} \mathrm{NaH}_{2} \mathrm{PO}_{4}$. The neutralized insoluble protein fraction was then assayed as above. Plates were measured for absorbance at $450 \mathrm{~nm}$ on a SpectraMax M2 plate reader and concentrations of $A \beta 1-40$ or $A \beta 1-42$ normalized to weight of brain sample used.

\section{Western Blotting}

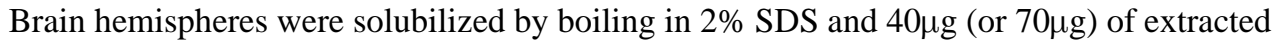
protein was separated on 10-20\% Tris-Tricine gradient polyacrylamide gels (Life Technologies, Grand Island, NY) and immunoblotted with anti-A $\beta 1-42$ (biotinylated 6E10, Covance SIG-39340-200) or GAPDH (Millipore, MAB374) as previously described(Wang et al., 2010). For PSD95 (Ab 12093, Abcam), synaptophysin (Ab 9272, Upstate

Biotechnology) and $\beta$-actin (49507, Cell Signaling) immunoblots, brain plasma membranes (cortex+hippocampus) were prepared and extracted using buffer A as previously described by Masliah and colleagues(Pham et al., 2010). Blots were developed using ECL chemiluminescence (Amersham, Piscataway, $\mathrm{NJ}$ ) and quantified as previously described(Jayasinha et al., 2003).

\section{Morris water maze tests}

Groups of 12 month-old (YOUNG) mock -or SDPM1-immunized APP/PS mice, or 18 month-old (OLD) mock -or SDPM1-immunized APP/PS mice, all time-matched to exactly 6 months after immunizations began, were tested in the Morris water maze, along with nonimmunized, age-matched, wild type mouse controls. All mice were blinded to the experimenter with respect to vaccination status and genotype. The tasks were conducted in a large pool (diameter $122 \mathrm{~cm}$ ) filled with $24^{\circ} \mathrm{C}$ water. Water was made opaque using nontoxic white paint. A hidden square platform $\left(10 \mathrm{~cm}^{2}\right)$ was placed $1 \mathrm{~cm}$ beneath the surface of the water in one quadrant of the pool. Visual cues were mounted on a screen surrounding the pool in fixed positions. The mice were pre-trained for 1 day to find and climb on to the hidden platform within 60 seconds of being placed in the water. If a mouse was unable to find the platform, it was placed there manually for 10 seconds. Mice were given up to three times to find the platform. Mice that were unable to find the platform during these training sessions were eliminated from the experiment. One or no animals per group were eliminated due to this criterion. Mice were then tested for 6 successive days, with four 60 -second trials per day, and escape time to platform (escape latency), swim speed and distance swum were recorded as before(Wang et al., 2010). A probe test to measure memory of the learned skill was done 12 hours after the final day of training as before(Wang et al., 2010).

\section{Open field tests}

Ambulatory movements were measured using a Photobeam Activity System (PAS, San Diego Instruments) open field test. All measurements were done in a dedicated mouse behavior room at the same time of day with defined temperature, ambient noise and ambient light. Each mouse was placed in the center of a 16- by 16-inch clear acrylic chamber with photobeams that run along its base at 1 inch spacing along the $\mathrm{X}$ - and $\mathrm{Y}$-axis. Ambulatory activity was recorded every time an animal crossed each one square-inch region of the box into another region. Movements were recorded in 45 -minute sessions for a total of 20 
minutes. Total recorded events were summed for each independent measure (fine motor, ambulatory, rearing) as before(Wang et al., 2010).

\section{Sequencing of P4D6 Antibody}

P4D6 heavy and light chains were sequenced from antibody chain mRNA transcripts amplified by RT-PCR from P4D6-expressing hybridoma cell clones by GenScript (Piscataway, NJ). Ten clones were sequenced from two different P4D6 expressing hybridoma cell variants, with all yielding the same single heavy chain sequence and the same single light chain sequence.

\section{Intracerebral P4D6 antibody injection}

15 month-old APP/PS mice were anaesthetized using isofluorane and kept under deep anesthesia for the remainder of the procedure. Surgery was performed using a stereotaxic apparatus (David Kopf Instruments; Tujunga, CA). The cranium was exposed by making an incision through the skin along the median sagittal plane. Four holes were drilled through the cranium of each animal, one each over the right and left frontal cortex injection site and one each over the right and left hippocampus injection site. Brain coordinates from brain surface were: +1.5 anterior-posterior, $-1.75 /+1.75$ mediolateral (right/left), -1.5 dorsoventral (frontal cortex) and -2.7 anterior-posterior, $-2.5 /+2.5$ mediolateral (right/left) and -2.0 dorsoventral (hippocampus). $2 \mu \mathrm{L}$ of purified P4D6 antibody ( $2 \mu \mathrm{g}$ total antibody) was dispensed on right side of the frontal cortex and hippocampus, each over a 4-minute period using a $10 \mu \mathrm{L}$ syringe, while $2 \mu \mathrm{L}$ of sterile PBS was similarly dispensed on the left side in each area as a control. The incision was then cleaned and closed with $3 \mathrm{M}$ Vetbond tissue adhesive and animals allowed to return to the colony after waking. 1 day or 14 days after injection, mice were anesthetized in ketamine and xylazine and perfused, via intracardiac perfusion, with PBS followed by $4 \%$ paraformaldehyde. Brains were removed and fixed further in $4 \%$ paraformaldehyde for 16 hours, after which they were washed in PBS, sunk in 10-30\% sucrose gradient, mounted in OCT, frozen in dry-ice cooled isopentane and sectioned for analysis.

\section{Cell culture assays of cell death}

SH-SY5Y cells (ATCC, Manassas, VA) were grown in a 1:1 mixture of Ham's F12 nutrient and Dulbecco's modified Eagle's medium (DMEM) supplemented with 10\% fetal bovine serum (FBS), $50 \mu \mathrm{g} / \mathrm{mL}$ penicillin, $50 \mathrm{U} / \mathrm{mL}$ streptomycin, $2 \mathrm{mM}$ glutamine and non-essential amino acids (Gibco, Gaithersburg, MD). Cells were incubated in a $95 \%$ air $5 \% \mathrm{CO}_{2}$ humidified incubator. For differentiation, cells were seeded in 96-well tissue culture plates at 30,000 cells per well for 1 day, after which medium was replaced with retinoic acid (RA) and 1\% N2 supplement (Invitrogen, Carlsbad, CA). One half of medium was replaced every other day for the ensuing 7 days, after which cell death experiments were performed.

For cell death experiments, $\mathrm{A} \beta 1-42$ was first diluted (from a DMSO stock) to make an aqueous $100 \mu \mathrm{M}$ A $\beta 1-42$ stock solution in PBS, with or without 5 $\mu$ M P4D6. A $\beta 1-42$ amyloid (+/-P4D6) was added to RA-differentiated SH-SY5Y cells for 48 hours in media in $2 \%$ fetal bovine serum. Cells were washed and assayed for Caspase 3/7 activity, cellular dye uptake or chromatin condensation. Caspase 3/7 assays were done using a fluorometric substratebased assay (Promega, Apo-ONE G7790) according to the manufacturer's instructions. To assay dye uptake and chromatin condensation, $10 \mu \mathrm{g} / \mathrm{mL}$ propidium iodide (Sigma, P-4864) and $10 \mu \mathrm{M}$ Hoechst 33342 (Invitrogen, H21492) were added in serum-free media to cells for 20 minutes. After removal of staining solution, cells were quickly washed in PBS and fixed in $4 \%$ paraformaldehyde. Cells positive for propidium iodide or condensed chromatin Hoechst staining were visualized and images quantified as previously described(Kelly et al., 
2003; Vaisid et al., 2008). A total of 600 cells were counted from each well, using at least 3 different, non-overlapping, 20x visual fields per well.

\section{$\mathrm{SDPM}_{4}$ production and binding experiments}

A cDNA encoding $\mathrm{SDPM}_{4}$ protein (AECDWGKGGRWRLWPGASGKTEACGPGAECDWGKGGRWRLWPGASGKTEACG PGAE CDWGKGGRWRLWPGASGKTEACGPGAECDWGKGGRWRLWPGASGKTEACGP) was subcloned into the HindIII and EcoR1 sites in the polylinker of pCVM1-FLAG vector to encode secreted, N-terminal FLAG epitope-tagged, protein. The plasmid was transfected into HEK293T cells and SDPM1 4 protein was purified from the cell supernatant using M2 (anti-FLAG)-agarose as previously described(Yoon et al., 2009). Eluted purified protein was quantified and used to determine relative binding to immobilized P4D6, A $\beta 1-40$ amyloid and A $\beta 1-42$ amyloid, as previously described(Wang et al., 2010).

\section{Statistics}

For comparison between only two groups, significance was determined using a two-tailed unpaired Student's $t$ test. For comparisons with more than two groups, significance was determined by ANOVA with post-hoc $t$ test.

\section{RESULTS}

\section{Immunization with SDPM1-ALUM vaccine reduces amyloid plaque burden in APPswePSEN1dE9 mouse brain}

To increase the translational potential of our experiments, we utilized ALUM as the adjuvant for our immunization protocol, as ALUM has been used extensively in clinical vaccines(Schijns and Lavelle, 2011). We first developed and optimized a vaccination method using SDPM1-ALUM as the immunogen to induce anti-SDPM1 and anti-A $\beta$ amyloid specific antibodies in wild type mice (Supplemental Figure 1). We next determined if our optimized immunization protocol could be used to affect brain $\mathrm{A} \beta$ amyloid burden, learning and memory, and the density of synaptic brain proteins in the APPswePSEN1dE9 (APP/PS) bitransgenic mouse model of Alzheimer's Disease (AD). We employed two vaccine paradigms, one aimed at understanding $\mathrm{AD}$ prevention and one aimed at understanding $\mathrm{AD}$ treatment. For the $\mathrm{AD}$ prevention paradigm, we immunized 6 month-old APP/PS mice (termed YOUNG), a time at which brain $\mathrm{A} \beta$ amyloid burden is first becoming evident(Borchelt et al., 1997; Jankowsky et al., 2001; Savonenko et al., 2005). For the AD treatment paradigm, we immunized 12 month-old APP/PS mice (termed OLD), a time at which brain A $\beta$ amyloid burden is already significant(Borchelt et al., 1997; Jankowsky et al., 2001; Savonenko et al., 2005). In both instances, mice were immunized once every two weeks with 100 $\mu \mathrm{g}$ SDPM1-ALUM for a total of four immunizations. Control animals included age-matched non-immunized wild type mice and APP/PS mice immunized with ALUM alone. All measures were performed 24 weeks, or 6 months, after the first immunization was given. No morbidity or mortality was noticed during either treatment regimen, and total serum IgG and IgE levels showed no treatment-induced elevation (not shown).

Both treatment paradigms led to 6-8-fold increases in serum antibodies specific for SDPM1 (Fig. 1A) and A $\beta 1-42$ amyloid (Fig. 1B). We repeated SDPM1 titers using subtype-specific secondary antibodies to determine the species of antibodies induced by SDPM1-ALUM vaccination (Fig. 1C). About half of all SDPM1 antibody, both in YOUNG and OLD, APP/ PS mice, was IgM. Most of the remaining antibody was IgG2b (about 30\%) or IgA (about $10 \%)$. 
We next assayed total brain $A \beta 1-40$ and $A \beta 1-42$ peptide levels (Fig. 2). $A \beta 1-40$ and $A \beta 1-42$ brain peptide levels were reduced by 50\% or more in YOUNG SDPM1-immunized APP/PS mice compared to mock-immunized APP/PS animals (Fig. 2A and C). Similar results were obtained in OLD APP/PS animals. Such reductions were significant in all instances, both in SDS-soluble (Fig. 2A) and SDS-insoluble fractions (Fig. 2C). Anti-A $\beta 1-42$ Western blots of whole brain SDS protein lysates, using the 6E10 antibody (Fig. 2B), showed a reduction in low molecular weight A $\beta$-containing peptides in SDPM1-immunized APP/PS brain relative to mock-immunized APP/PS controls. The APPswe transgenic protein and the endogenous brain APP protein also contain the A $\beta 1-42$ peptide recognized by $6 \mathrm{E} 10(120 \mathrm{kDa}$ band in Fig. 2B). SDPM1 immunization did not significantly lower transgenic overexpression of APPswe protein in APP/PS brain.

The reduction in overall brain $\mathrm{A} \beta$ peptide levels was further supported by staining SDPM1and mock-immunized APP/PS brains with Thioflavin S, which stains dense core A $\beta$ amyloid aggregates (Fig. 3A). Amyloid plaque burden, as a percentage of brain area, was reduced by $50 \%$ or more in both YOUNG and OLD SDPM1-immunized hippocampus and cortex (Fig. 3B). This was similarly correlated with a reduction in amyloid plaque number (Fig. 3C) and the average size of individual amyloid plaques in most instances (Fig. 3D). All such analyses were quantified using samples blinded to the investigators as to treatment and genotype.

\section{Immunization with SDPM1-ALUM improves learning and memory in APP/PS mice}

Aside from brain amyloid plaque burden, the best outcome measure to judge clinical efficacy in APP/PS mice is the ability to improve measures of learning and memory. Prior to sacrifice, we subjected YOUNG and OLD SDPM1-immunized and mock-immunized APP/ PS mice to such tests in the Morris water maze, comparing them also to non-immunized, age-matched, wild type animals (Fig. 4). By 12 months of age (the time point at which YOUNG immunized APP/PS mice were analyzed), APP/PS mice show significant deficits in learning relative to wild type animals (Fig. 4A). This was reflected in their inability to learn with repeated training to escape swimming by climbing onto a spatially fixed, but invisible, platform using spatially fixed visual cues. Both APP/PS and wild type mice, prior to training, took 40-50 seconds to complete this task. With repeated training, wild type mice learned to perform this task in half the amount of time (by days 5-6), while mockimmunized APP/PS mice did not (Fig. 4A). Improved learning, showing a significant difference compared to mock-immunized APP/PS animals, occurred in both YOUNG and OLD SDPM1-immunized APP/PS mice by 5 and 6 days of training (Fig. 4A and 4D).

After training was completed, mice were given 12 hours without training and then subjected to a probe test for memory of the learned skill. SDPM1-immunized APP/PS mice approached memory levels observed in wild type animals, and this differed significantly from mock-immunized APP/PS animals (Fig. 4B and 4E). This was the case in both YOUNG and in OLD SDPM1-immunized APP/PS mice. Analysis of all three groups at the two different ages showed no significant difference in swim speed between any two groups (Fig. 4C and 4F). Thus, differences between groups did not result from an altered ability to swim. Open field tests of ambulation, fine motor activity, and rearing also showed no significant difference between any groups (data not shown).

\section{Immunization with SDPM1-ALUM increases expression of synaptic proteins in APP/PS brain}

Akin to alterations in cognitive performance, APP/PS mice show altered expression of synaptic brain proteins, much as can also occur in $\mathrm{AD}$ (Buttini et al., 2005; DeKosky and Scheff, 1990; Masliah et al., 1991; Pham et al., 2010; Sze et al., 1997; Terry et al., 1991). 
Therefore, we next assessed and quantified the expression of synaptophysin, a presynaptic vesicle marker of synaptic density, by immunostaining and immunoblotting (Fig 5). We identified a significant decrease in synaptophysin staining in both the frontal cortex and the molecular layer of the hippocampus in OLD mock-immunized APP/PS mice compared to wild type mice. Synaptophysin staining density was significantly increased in both brain regions of OLD SDPM1-immunized APP/PS mice compared to mock-immunized APP/PS animals (Figs. 5A and C). We also assayed for the expression of synaptic proteins by immunoblotting of purified brain membranes isolated from cortex and hippocampus, which were pooled for each animal (Figs. 5B and D). We found a significant reduction in synaptophysin protein, and also a reduction in the postsynaptic glutamate receptor anchoring protein PSD95, in OLD mock-immunized APP/PS mice compared to wild type mice (Fig. 5B and D). Levels of both proteins were significantly increased in OLD SDPM1-immunized APP/PS mice compared to mock-immunized APP/PS animals (Fig. 5D). For both staining and blotting, similar trends were observed in YOUNG animals, though these differences were not always significant. Thus, the positive changes of SDPM1 immunization on cognitive performance correlated with increased expression of synaptic proteins, including synaptophysin and PSD95.

\section{Reduced inflammatory markers in SDPM1-immunized APP/PS brain}

To assess overall levels of inflammatory cells, we quantified positive cell staining in brain sections taken from SDPM1- and mock-immunized APP/PS mouse cortex for GFAP, a marker for astrocytes (and whose increased expression marks astroglial activation and gliosis), Iba1, a marker for brain microglia, and CD68, a marker for activated brain microglia (Fig. 6). Consistent with reduced amyloid plaque burden, we saw a significant reduction in CD68-positive cells in both YOUNG and OLD SDPM1-immunized APP/PS brain, relative to mock-immunized APP/PS controls. In addition, we did not observe any significant increase in brain Iba1 or GFAP positive cells in SDPM1-immunized APP/PS brain. No staining for T or B cells (using antibodies to CD45, CD4, CD8 or B220) was found in grey or white matter of SDPM1-immunized APP/PS brain, nor was any increased staining evident in the meninges (not shown). These data suggest that there is no increase in brain inflammation as the result of SDPM1 immunization.

\section{Therapeutic response of APP/PS mice to passive vaccination with P4D6, an SDPM1 peptide-mimotope antibody}

We had previously shown that peptide-mimotope antibodies induced by SDPM1 immunization can, like the SDPM1 peptide itself, bind to low molecular weight A $\beta$ amyloid oligomers and block subsequent $A \beta$ amyloid aggregation(Wang et al., 2010). One such antibody is P4D6. Co-staining of P4D6 with Thioflavin S in 15 month-old APP/PS brain shows that P4D6 recognizes regions at the periphery of dense core amyloid plaques in sections taken from the frontal cortex (Supplemental Fig. 2).

We next determined if intracerebral injection of P4D6 would reduce $A \beta$ amyloid plaque burden at the site of injection, much as other anti-A $\beta$ peptide antibodies are known to do(Delrieu et al., 2012; Laskowitz and Kolls, 2010; Ostrowitzki et al., 2012; Panza et al., 2012; Roher et al., 2011). We used stereotactic brain injection methods to focally introduce P4D6 into a region of the frontal cortex and the hippocampus in 15 month-old APP/PS mice. The contralateral side of the brain was similarly injected (both cortex and hippocampus) with vehicle alone. At 1 day post-injection, we could identify diffuse, evenly distributed, staining of P4D6 antibody on the injected side of the brain, where it was concentrated at dense core amyloid plaques (co-stained with Thioflavin S) (Supplemental Fig. 3). By contrast, injected P4D6 did not co-localize with microglia (stained with Iba1) (Supplemental 
Fig. 3). Staining of the contralateral (control) side of the brain showed very low background in the absence of P4D6 (Supplemental Fig. 3).

By two weeks post-injection, most of the injected P4D6 antibody had been taken up by cells or cleared from the brain. Cellular staining of internalized antibody, however, was still visible in injected regions of the hippocampus (Fig. 7A) and cortex (Fig. 7B). Co-staining for P4D6 and Thioflavin S showed reduced Thioflavin S staining in P4D6-injected brain regions. Amyloid plaque burden (Fig. 7C) and plaque number (Fig. 7D) were both significantly reduced in P4D6-injected areas. Interestingly, the size of remaining plaques (Fig. 7E), most of which were present at the edges of the injection sites, was unchanged, suggesting a local therapeutic effect at the site of injection. These data demonstrate that an SDPM1 peptide-mimotope antibody can directly affect brain $\mathrm{A} \beta$ amyloid plaque burden.

\section{P4D6 inhibits $A \beta$ amyloid-mediated neurotoxicity}

Because APP/PS mice fail to properly model the full extent of neurodegeneration that occurs in $\mathrm{AD}$, we tested whether P4D6 could block $\mathrm{A} \beta$-mediated neurotoxicity using neuronally differentiated SH-SY5Y cells(Lambert et al., 1994; Pahlman et al., 1984). We performed three assays to address neurotoxicity. The first was a fluorescence-activated Caspase 3/7 activity assay, which models activation of $\mathrm{A} \beta$-mediated apoptosis, the second was propidium iodide uptake, which models cell death via perforation of the cell membrane, and the third was quantification of chromatin condensation via Hoechst staining of nuclei in dying cells. We performed these experiments by first making a $100 \mu \mathrm{M} A \beta 1-42$ peptide solution in PBS either in the presence or the absence of 5 $\mu \mathrm{M}$ P4D6. Serial dilutions of these two stock solutions were then used for all experiments. Differing dilutions of this stock solution, (either of A $\beta 1-42$ alone or A $\beta 1-42+\mathrm{P} 4 \mathrm{D} 6$ ) were added to differentiated SH-SY5Y cells for 48 hours for each assay. For all three assays, we observed blockage of A $\beta 1-42$ mediated neurotoxicity by P4D6 (Fig. 8). All such changes were significant at 5, 10 and $20 \mu \mathrm{M}$ added $\mathrm{A} \beta 1-42$. These data support the notion that P4D6 can inhibit $\mathrm{A} \beta$-mediated neurotoxicity and cell death.

\section{Sequencing of the P4D6 antibody and SDPM1 multimer binding}

To identify the P4D6 antibody sequence, we used RT-PCR to subclone and sequence multiple mouse antibody heavy and light chain clones from multiple P4D6-expressing hybridoma cell clones. All heavy chain sequences identified were identical, as were all light chain sequences identified. These findings suggest a true clonal nature to the P4D6 hybridomas we had originally made (Supplemental Fig. 4). Moreover, heavy chain and light chains sequences were consistent with previous characterization of P4D6 as a mu-heavy chain/lambda-light chain antibody(Wang et al., 2010).

There are four common features in the amino acid sequence of SDPM1 and SDPM1-like peptides(Kang et al., 2003; Wang et al., 2010). First, all such peptides require a cysteine at both ends of the peptide for high affinity binding to $A \beta$ amyloid. Second, they are all rich in hydrophobic amino acids. Third, they all have a net positive charge, and fourth, they all contain a proline within the hydrophobic-basic region. In analyzing the 73 amino acid variable domain of the P4D6 heavy chain bounded by cysteines, we identified two SDPM1like motifs in the P4D6 heavy chain (Fig. 9A). Each SDPM1-like motif was rich in hydrophobic amino acids, had an abundance of lysine and arginine (with net positive charge of +2 per motif) and contained a proline. No SDPM1-like motifs were evident in the variable domain of the P4D6 light chain (Fig. 9A).

We had previously shown that the SDPM1 peptide has a lower binding affinity for $\mathrm{A} \beta$ amyloid than does P4D6(Wang et al., 2010). Binding of monomeric SDPM1 to A $\beta 1-40$ and 
to $\mathrm{A} \beta 1-42$ amyloid was saturable at $1 \mu \mathrm{M}$, while binding of P4D6 to these same proteins was saturable at $15 \mathrm{nM}$. To determine if this could be due to the multimeric presentation of SDPM1 in P4D6, which theoretically would have four SDPM1 motifs per Ig domain, we produced a recombinant tetrameric form of the SDPM1 peptide (SDPM1 $1_{4}$ ). SDPM1 $1_{4}$ showed high affinity binding to $\mathrm{P} 4 \mathrm{D6}$, and this binding was nearly identical in profile to $\mathrm{SDPM}_{4}$ binding to $\mathrm{A} \beta 1-40$ and $\mathrm{A} \beta 1-42$ amyloid (Fig. 9B). Binding of SDPM1 4 to all three proteins was saturable at $15 \mathrm{nM}$ (Fig. 9B). Thus, multimerization of the SDPM1 motif, much as may occur in P4D6, increased binding to $\mathrm{A} \beta$ amyloid by $1-2 \operatorname{logs}$ relative to the monomeric peptide.

\section{DISCUSSION}

We have demonstrated that immunization of APPswePSEN1delE9 (APP/PS) mice with SDPM1, an A $\beta$-amyloid specific binding and blocking peptide(Kang et al., 2003; Wang et al., 2010), reduces brain amyloid plaque burden and brain $A \beta 1-40$ and $A \beta 1-42$ peptide levels, improves learning and memory, and increases expression of synaptic brain proteins. The immunization protocol was optimized for its translational relevance by utilizing ALUM as the adjuvant and only four immunizations for the vaccine paradigm. YOUNG (6 monthold) APP/PS mice, immunized just as brain A $\beta$ amyloid plaques were developing(Borchelt et al., 1997), and OLD (12 month-old) APP/PS mice, immunized after brain amyloid burden was already significant(Borchelt et al., 1997), both showed improvements in most or all of these measures when analyzed 6 months after immunizations were begun. In addition, we found no increase in inflammatory cells in the brains of either YOUNG or OLD APP/PS mice compared to age-matched APP/PS controls. Thus, immunization with the SDPM1 peptide bound to ALUM shows potential as a vaccine therapy for Alzheimer's disease.

Previously, we had shown that immunization with biotinylated SDPM1 (conjugated to streptavidin and coupled with Freund's incomplete adjuvant) stimulated production of SDPM1-specific antibodies that cleared brain $A \beta$ amyloid plaque burden and improved learning and memory in APPswePSEN1(A246E) mice(Wang et al., 2010). Besides the use of a different mouse model here, there were several other important differences between the two studies. First, our previous study showed improvements in learning and memory in YOUNG, but not OLD, APP/PS mice, while here both YOUNG and OLD APP/PS SDPM1immunized animals showed significant cognitive improvement. Use of the ALUM-SDPM1 vaccine stimulated roughly the same amounts of SDPM1-specific and A $\beta$ amyloid-specific antibodies as was seen in the previous study, but the vaccine paradigm used here, four injections (one every two weeks) versus 6 injections previously (one every month) may have led to more rapid therapeutic antibody production. Second, the distribution of SDPM1specific antibody species produced in the two studies was different; the biotin-SDPM1strepavidin vaccine produced anti-SDPM1-specific antibodies that were predominantly IgG1 (65-85\%) with most of the remainder being IgM (10-20\%), while the SDPM1-ALUM vaccine produced predominantly IgM (45-55\%) with most of the remainder being IgG2b $(25-30 \%)$ or IgA (10\%). Both SDPM1 vaccines were strongly biased towards a Th2 type immune response(Finkelman et al., 1990), with $\mathrm{IgG1}+\mathrm{IgG} 2 \mathrm{~b}$ antibody levels being roughly 10 -fold higher than $\operatorname{IgG} 2 \mathrm{a}$. The preferential production of $\operatorname{IgG} 2 \mathrm{~b}$ and $\operatorname{IgA}$ here perhaps suggests a TGF $\beta$-mediated, Treg-dependent, mechanism for T cell help, as TGF $\beta$ can be produced by Treg cells and can induce IgG2b and IgA class switching(Josefowicz et al., 2012; Park et al., 2005; Tran, 2012). Third, in this study we have correlated improvements in cognitive performance here with increased expression of synaptic brain proteins (synaptophysin and PSD95). This data is consistent with previous studies showing reduced staining and blotting for synaptic proteins in both AD and APP/PS brain, suggestive of changed synaptic density and/or integrity, and increased expression after immunization with A $\beta$ peptides (Buttini et al., 2005; Buttini et al., 2002; DeKosky and Scheff, 1990; Masliah et 
al., 1991; Pham et al., 2010; Scheff and Price, 2003; Shankar et al., 2009; Terry et al., 1991). Improvements in cognitive performance, however, may also reflect the decreased brain inflammation in SDPM1-vaccinated animals. Fourth, the vaccine paradigm utilized here is more translationally relevant for AD than our previous study. Formulation of a clinical vaccine as has been used in this study would only require cGMP production of the SDPM1-4E peptide and its conjugation with ALUM, an adjuvant that has been used in many clinical vaccines(Schijns and Lavelle, 2011).

The SDPM1-ALUM vaccine joins a large number of proof of concept experiments showing that immunization with various formulations of $A \beta$ peptide can have therapeutic effects in AD mouse models(Delrieu et al., 2012; Lemere and Masliah, 2010; Nelson et al., 2012; Panza et al., 2012; Tabira, 2010). The relevant question, then, is why would SDPM1 be any better than these myriad other approaches. Several features of SDPM1 recommend its use. The first, and most obvious, is that the SDPM1 peptide is not structurally related to the $\mathrm{A} \beta 1-40$ or $\mathrm{A} \beta 1-42$ peptide. SDPM1 was isolated as binding to $A \beta$ amyloid from a cysteinelinked random 20 amino acid phage display peptide library(Kang et al., 2003). To our knowledge, this peptide sequence does not exist in nature, showing no more than 50\% identity to any protein in any database. As such, it represents a non-native protein sequence, which in turn, perhaps, also reflects a non-native immunogenic epitope. The issue of endogenous protein homology is very important for the effectiveness of an $\mathrm{AD}$ vaccine. Only a minority of the AD patients in the AN1792 trial, where A $\beta 1-42$ amyloid was used as the immunogen, produced increased levels of anti-A $\beta$ antibodies (Gilman et al., 2005; Orgogozo et al., 2003; Schenk, 2008). Such failures arise, at least in part, from the reduced responsiveness of elderly patients to vaccines(Chen et al., 2009; Grubeck-Loebenstein et al., 2009; Haynes and Swain, 2006). An additional issue, however, may be the endogenous expression of A $\beta 1-42$ within APP and its natural release by $\beta$ and $\gamma$ secretase, which could tolerize patient immune responses to A $\beta 1-42$ immunization. Second, immunization with SDPM1 induces peptide-mimotope antibodies such as P4D6 that specifically bind to and affect low molecular weight $\mathrm{A} \beta$ oligomers(Wang et al., 2010). We show here that P4D6 can directly clear amyloid plaque burden in APP/PS brain and can block A $\beta$-mediated neurotoxicity in cultured neuron-like cells. While immunization with $A \beta$ peptides would also allow for immune responses to low molecular weight $A \beta$ oligomers, such $A \beta$ oligomers would likely only be present in small amounts, as A $\beta 1-42$ oligomerization to high molecular weight forms occurs quite rapidly. Both passive and active anti-A $\beta$ immunization vaccine strategies can have toxic side effects that can be antibody- or lymphocyte-mediated, including meningoencephalitis, vasogenic cerebral edema, and microhemmorhage(Delrieu et al., 2012; Laskowitz and Kolls, 2010; Monsonego et al., 2003; Orgogozo et al., 2003). The ability to eliminate such side effects by targeting a specific subset of $A \beta$ oligomers could be very important. The sequencing of the P4D6 antibody also allows for the creation of humanized antibodies to test in future studies.

Other studies suggest that the SDPM1 motif may be part of a class of peptide sequences that abrogate common protein amyloid aggregation domains within pathologic proteins. For examples, O'Nuallain and colleagues used phage display to map peptides that could mimic binding of the 11-1F4 antibody to the human $\kappa 4$ Bence Jones protein Len, a protein cause of non-A $\beta$ amyloidosis(O'Nuallain et al., 2007). Like P4D6, 11-1F4 shows therapeutic efficacy at inhibiting amyloidosis in vivo and protein fibrillogenesis in vitro(Hrncic et al., 2000; O'Nuallain et al., 2007). Similar to SDPM1, they identified only proteins with a proline flanked by aromatic amino acids, suggesting a hydrophobic cis-proline-mediated $\beta$ turn was involved in aberrant protein aggregation. Another study by Tanaka and colleagues showed a hydrophobic and positively charged motif in the B6-C15 cyclic peptide could block A $\beta 1-42$ fibrillogenesis, again defining positively charged and hydrophobic amino acids (with a proline) as being important for blocking protein aggregation(Tanaka et al., 2011). 
Interestingly, like SDPM1 and P4D6(Wang et al., 2010), the B6-C15 peptide appeared to block $A \beta$ aggregation at the level of $A \beta$ tetramers(Tanaka et al., 2011). Thus, while not identical to the sequence we have identified, these studies support the notion that SDPM1like peptide motifs can have therapeutic efficacy in $\mathrm{AD}$ and perhaps other forms of protein amyloidosis.

\section{Supplementary Material}

Refer to Web version on PubMed Central for supplementary material.

\section{Acknowledgments}

We would like to thank Leslie Turner for technical support. Leslie was supported by the NCH high school summer scientist's internship program. This work was supported by NIH grant AR049722 to PTM and by a Technology Transfer grant from Nationwide Children's Hospital to PTM.

\section{References}

Bachman DL, et al. Prevalence of dementia and probable senile dementia of the Alzheimer type in the Framingham Study. Neurology. 1992; 42:115-9. [PubMed: 1734291]

Bard F, et al. Epitope and isotype specificities of antibodies to beta -amyloid peptide for protection against Alzheimer's disease-like neuropathology. Proc Natl Acad Sci U S A. 2003; 100:2023-8. [PubMed: 12566568]

Barghorn S, et al. Globular amyloid beta-peptide oligomer - a homogenous and stable neuropathological protein in Alzheimer's disease. J Neurochem. 2005; 95:834-47. [PubMed: 16135089]

Borchelt DR, et al. Accelerated amyloid deposition in the brains of transgenic mice coexpressing mutant presenilin 1 and amyloid precursor proteins. Neuron. 1997; 19:939-45. [PubMed: 9354339]

Buttini M, et al. Beta-amyloid immunotherapy prevents synaptic degeneration in a mouse model of Alzheimer's disease. J Neurosci. 2005; 25:9096-101. [PubMed: 16207868]

Buttini M, et al. Modulation of Alzheimer-like synaptic and cholinergic deficits in transgenic mice by human apolipoprotein E depends on isoform, aging, and overexpression of amyloid beta peptides but not on plaque formation. J Neurosci. 2002; 22:10539-48. [PubMed: 12486146]

Carty NC, et al. Intracranial administration of deglycosylated C-terminal-specific anti-Abeta antibody efficiently clears amyloid plaques without activating microglia in amyloid-depositing transgenic mice. Journal of neuroinflammation. 2006; 3:11. [PubMed: 16686956]

Chen WH, et al. Vaccination in the elderly: an immunological perspective. Trends Immunol. 2009; 30:351-9. [PubMed: 19540808]

Cleary JP, et al. Natural oligomers of the amyloid-beta protein specifically disrupt cognitive function. Nat Neurosci. 2005; 8:79-84. [PubMed: 15608634]

Cribbs DH. Abeta DNA vaccination for Alzheimer's disease: focus on disease prevention. CNS Neurol Disord Drug Targets. 2010; 9:207-16. [PubMed: 20205639]

DeKosky ST, Scheff SW. Synapse loss in frontal cortex biopsies in Alzheimer's disease: correlation with cognitive severity. Ann Neurol. 1990; 27:457-64. [PubMed: 2360787]

Delrieu J, et al. 'Clinical trials in Alzheimer's disease': immunotherapy approaches. J Neurochem. 2012; 120(Suppl 1):186-93. [PubMed: 21883222]

DeMattos RB, et al. Peripheral anti-A beta antibody alters CNS and plasma A beta clearance and decreases brain A beta burden in a mouse model of Alzheimer's disease. Proc Natl Acad Sci U S A. 2001; 98:8850-5. [PubMed: 11438712]

Finkelman FD, et al. Lymphokine control of in vivo immunoglobulin isotype selection. Annu Rev Immunol. 1990; 8:303-33. [PubMed: 1693082]

Ghochikyan A, et al. Prototype Alzheimer's disease epitope vaccine induced strong Th2-type antiAbeta antibody response with Alum to Quil A adjuvant switch. Vaccine. 2006; 24:2275-82.

[PubMed: 16368167] 
Gilman S, et al. Clinical effects of Abeta immunization (AN1792) in patients with AD in an interrupted trial. Neurology. 2005; 64:1553-62. [PubMed: 15883316]

Grubeck-Loebenstein B, et al. Immunosenescence and vaccine failure in the elderly. Aging Clin Exp Res. 2009; 21:201-9. [PubMed: 19571643]

Hardy JA, Higgins GA. Alzheimer's disease: the amyloid cascade hypothesis. Science. 1992; 256:184-5. [PubMed: 1566067]

Haynes L, Swain SL. Why aging T cells fail: implications for vaccination. Immunity. 2006; 24:663-6. [PubMed: 16782020]

Hock C, et al. Antibodies against beta-amyloid slow cognitive decline in Alzheimer's disease. Neuron. 2003; 38:547-54. [PubMed: 12765607]

Hrncic R, et al. Antibody-mediated resolution of light chain-associated amyloid deposits. Am J Pathol. 2000; 157:1239-46. [PubMed: 11021828]

Hsieh H, et al. AMPAR removal underlies Abeta-induced synaptic depression and dendritic spine loss. Neuron. 2006; 52:831-43. [PubMed: 17145504]

Jankowsky JL, et al. Co-expression of multiple transgenes in mouse CNS: a comparison of strategies. Biomol Eng. 2001; 17:157-65. [PubMed: 11337275]

Jayasinha V, et al. Inhibition of dystroglycan cleavage causes muscular dystrophy in transgenic mice. Neuromuscul Disord. 2003; 13:365-75. [PubMed: 12798792]

Josefowicz SZ, et al. Regulatory T cells: mechanisms of differentiation and function. Annu Rev Immunol. 2012; 30:531-64. [PubMed: 22224781]

Kang CK, et al. Identification of peptides that specifically bind Abeta1-40 amyloid in vitro and amyloid plaques in Alzheimer's disease brain using phage display. Neurobiol Dis. 2003; 14:14656. [PubMed: 13678675]

Kelly KJ, et al. A novel method to determine specificity and sensitivity of the TUNEL reaction in the quantitation of apoptosis. Am J Physiol Cell Physiol. 2003; 284:C1309-18. [PubMed: 12676658]

$\mathrm{Kim} \mathrm{JH}$, et al. Use-dependent effects of amyloidogenic fragments of (beta)-amyloid precursor protein on synaptic plasticity in rat hippocampus in vivo. J Neurosci. 2001; 21:1327-33. [PubMed: 11160403]

Lace GL, et al. A brief history of tau: the evolving view of the microtubule-associated protein tau in neurodegenerative diseases. Clin Neuropathol. 2007; 26:43-58. [PubMed: 17416103]

Lambert MP, et al. Diffusible, nonfibrillar ligands derived from Abeta1-42 are potent central nervous system neurotoxins. Proc Natl Acad Sci U S A. 1998; 95:6448-53. [PubMed: 9600986]

Lambert MP, et al. Beta/A4-evoked degeneration of differentiated SH-SY5Y human neuroblastoma cells. J Neurosci Res. 1994; 39:377-85. [PubMed: 7533843]

Laskowitz DT, Kolls BJ. A phase 2 multiple ascending dose trial of bapineuzumab in mild to moderate Alzheimer disease. Neurology. 2010; 74:2026. author reply 2026-7. [PubMed: 20548049]

Lemere CA. Developing novel immunogens for a safe and effective Alzheimer's disease vaccine. Prog Brain Res. 2009; 175:83-93. [PubMed: 19660650]

Lemere CA, Masliah E. Can Alzheimer disease be prevented by amyloid-beta immunotherapy? Nat Rev Neurol. 2010; 6:108-19. [PubMed: 20140000]

Lesne S, et al. A specific amyloid-beta protein assembly in the brain impairs memory. Nature. 2006; 440:352-7. [PubMed: 16541076]

Levites Y, et al. Anti-Abeta42- and anti-Abeta40-specific mAbs attenuate amyloid deposition in an Alzheimer disease mouse model. The Journal of clinical investigation. 2006a; 116:193-201. [PubMed: 16341263]

Levites Y, et al. Intracranial adeno-associated virus-mediated delivery of anti-pan amyloid beta, amyloid beta40, and amyloid beta42 single-chain variable fragments attenuates plaque pathology in amyloid precursor protein mice. The Journal of neuroscience: the official journal of the Society for Neuroscience. 2006b; 26:11923-8. [PubMed: 17108166]

Marcello E, et al. Synaptic dysfunction in Alzheimer's disease. Adv Exp Med Biol. 2012; 970:573601. [PubMed: 22351073]

Masliah E, et al. Cortical and subcortical patterns of synaptophysinlike immunoreactivity in Alzheimer's disease. Am J Pathol. 1991; 138:235-46. [PubMed: 1899001] 
Monsonego A, et al. Increased T cell reactivity to amyloid beta protein in older humans and patients with Alzheimer disease. J Clin Invest. 2003; 112:415-22. [PubMed: 12897209]

Morrissette DA, et al. Relevance of transgenic mouse models to human Alzheimer disease. J Biol Chem. 2009; 284:6033-7. [PubMed: 18948253]

Nelson PT, et al. Correlation of Alzheimer disease neuropathologic changes with cognitive status: a review of the literature. J Neuropathol Exp Neurol. 2012; 71:362-81. [PubMed: 22487856]

Nicoll JA, et al. Abeta species removal after abeta42 immunization. J Neuropathol Exp Neurol. 2006; 65:1040-8. [PubMed: 17086100]

O'Nuallain B, et al. Phage display and peptide mapping of an immunoglobulin light chain fibril-related conformational epitope. Biochemistry. 2007; 46:13049-58. [PubMed: 17944486]

Orgogozo JM, et al. Subacute meningoencephalitis in a subset of patients with AD after Abeta42 immunization. Neurology. 2003; 61:46-54. [PubMed: 12847155]

Ostrowitzki S, et al. Mechanism of amyloid removal in patients with Alzheimer disease treated with gantenerumab. Arch Neurol. 2012; 69:198-207. [PubMed: 21987394]

Pahlman S, et al. Retinoic acid-induced differentiation of cultured human neuroblastoma cells: a comparison with phorbolester-induced differentiation. Cell Differ. 1984; 14:135-44. [PubMed: 6467378]

Panza F, et al. Immunotherapy for Alzheimer's disease: from anti-beta-amyloid to tau-based immunization strategies. Immunotherapy. 2012; 4:213-38. [PubMed: 22339463]

Park SR, et al. Analysis of transforming growth factor-beta1-induced Ig germ-line gamma2b transcription and its implication for IgA isotype switching. Eur J Immunol. 2005; 35:946-56. [PubMed: 15688346]

Pham E, et al. Progressive accumulation of amyloid-beta oligomers in Alzheimer's disease and in amyloid precursor protein transgenic mice is accompanied by selective alterations in synaptic scaffold proteins. FEBS J. 2010; 277:3051-67. [PubMed: 20573181]

Pride M, et al. Progress in the active immunotherapeutic approach to Alzheimer's disease: clinical investigations into AN1792-associated meningoencephalitis. Neurodegener Dis. 2008; 5:194-6. [PubMed: 18322388]

Roher AE, et al. Neuropathology and amyloid-beta spectrum in a bapineuzumab immunotherapy recipient. Journal of Alzheimer's disease: JAD. 2011; 24:315-25.

Savonenko A, et al. Episodic-like memory deficits in the APPswe/PS1dE9 mouse model of Alzheimer's disease: relationships to beta-amyloid deposition and neurotransmitter abnormalities. Neurobiol Dis. 2005; 18:602-17. [PubMed: 15755686]

Scheff SW, Price DA. Synaptic pathology in Alzheimer's disease: a review of ultrastructural studies. Neurobiol Aging. 2003; 24:1029-46. [PubMed: 14643375]

Schenk D. Current challenges for the successful treatment and prevention of Alzheimer's disease: treating the pathologies of the disease to change its clinical course. Alzheimers Dement. 2008; 4:S119-21. [PubMed: 18631987]

Schenk D, et al. Immunization with amyloid-beta attenuates Alzheimer-disease-like pathology in the PDAPP mouse. Nature. 1999; 400:173-7. [PubMed: 10408445]

Schijns VE, Lavelle EC. Trends in vaccine adjuvants. Expert Rev Vaccines. 2011; 10:539-50. [PubMed: 21506650]

Schneeberger A, et al. Development of AFFITOPE vaccines for Alzheimer's disease (AD)--from concept to clinical testing. J Nutr Health Aging. 2009; 13:264-7. [PubMed: 19262965]

Selkoe DJ. Alzheimer's disease results from the cerebral accumulation and cytotoxicity of amyloid beta-protein. J Alzheimers Dis. 2001a; 3:75-80. [PubMed: 12214075]

Selkoe DJ. Alzheimer's disease: genes, proteins, and therapy. Physiol Rev. 2001b; 81:741-66. [PubMed: 11274343]

Shankar GM, et al. Natural oligomers of the Alzheimer amyloid-beta protein induce reversible synapse loss by modulating an NMDA-type glutamate receptor-dependent signaling pathway. J Neurosci. 2007; 27:2866-75. [PubMed: 17360908] 
Shankar GM, et al. Biochemical and immunohistochemical analysis of an Alzheimer's disease mouse model reveals the presence of multiple cerebral Abeta assembly forms throughout life. Neurobiol Dis. 2009; 36:293-302. [PubMed: 19660551]

Shankar GM, et al. Amyloid-beta protein dimers isolated directly from Alzheimer's brains impair synaptic plasticity and memory. Nat Med. 2008; 14:837-42. [PubMed: 18568035]

Sze CI, et al. Loss of the presynaptic vesicle protein synaptophysin in hippocampus correlates with cognitive decline in Alzheimer disease. J Neuropathol Exp Neurol. 1997; 56:933-44. [PubMed: 9258263]

Tabira T. Immunization therapy for Alzheimer disease: a comprehensive review of active immunization strategies. Tohoku J Exp Med. 2010; 220:95-106. [PubMed: 20139660]

Tanaka K, et al. A mimotope peptide of Abeta42 fibril-specific antibodies with Abeta42 fibrillation inhibitory activity induces anti-Abeta42 conformer antibody response by a displayed form on an M13 phage in mice. J Neuroimmunol. 2011; 236:27-38. [PubMed: 21641049]

Terry RD. The pathogenesis of Alzheimer disease: an alternative to the amyloid hypothesis. $\mathrm{J}$ Neuropathol Exp Neurol. 1996; 55:1023-5. [PubMed: 8857998]

Terry RD, et al. Physical basis of cognitive alterations in Alzheimer's disease: synapse loss is the major correlate of cognitive impairment. Ann Neurol. 1991; 30:572-80. [PubMed: 1789684]

Tran DQ. TGF-beta: the sword, the wand, and the shield of FOXP3(+) regulatory T cells. J Mol Cell Biol. 2012; 4:29-37. [PubMed: 22158907]

Vaisid T, et al. Amyloid beta peptide toxicity in differentiated PC12 cells: calpain-calpastatin, caspase, and membrane damage. J Neurosci Res. 2008; 86:2314-25. [PubMed: 18438916]

Walsh DM, et al. Naturally secreted oligomers of amyloid beta protein potently inhibit hippocampal long-term potentiation in vivo. Nature. 2002; 416:535-9. [PubMed: 11932745]

Wang CM, et al. Immunization with the SDPM1 peptide lowers amyloid plaque burden and improves cognitive function in the APPswePSEN1(A246E) transgenic mouse model of Alzheimer's disease. Neurobiol Dis. 2010; 39:409-22. [PubMed: 20493257]

Wei W, et al. Amyloid beta from axons and dendrites reduces local spine number and plasticity. Nat Neurosci. 2010; 13:190-6. [PubMed: 20037574]

Wilcock DM, et al. Intracranially administered anti-Abeta antibodies reduce beta-amyloid deposition by mechanisms both independent of and associated with microglial activation. The Journal of neuroscience: the official journal of the Society for Neuroscience. 2003; 23:3745-51. [PubMed: 12736345]

Yamada K, et al. Abeta immunotherapy: intracerebral sequestration of Abeta by an anti-Abeta monoclonal antibody 266 with high affinity to soluble Abeta. J Neurosci. 2009; 29:11393-8. [PubMed: 19741145]

Yoon JH, et al. The synaptic CT carbohydrate modulates binding and expression of extracellular matrix proteins in skeletal muscle: Partial dependence on utrophin. Mol Cell Neurosci. 2009; 41:448-63. [PubMed: 19442736] 


\section{Highlights}

Vaccination with SDPM1 shows pre-clinical efficacy in lowering brain A $\beta$ amyloid plaque burden, brain $A \beta 1-40$ and $A \beta 1-42$ peptide levels, and improving learning and memory and expression of synaptic proteins in the APPswePSEN1de9 mouse.

An SDPM1 peptide-mimotope antibody, P4D6, can lower brain A $\beta$ amyloid plaque burden in the APPswePSENde9 mouse

An SDPM1 peptide-mimotope antibody, P4D6, can block A $\beta$-mediated neurotoxicity

The therapeutic SDPM1 peptide-mimotope antibody, P4D6, was sequenced and mimics the SDPM1 peptide motif in the variable domain of its heavy chain. 
A

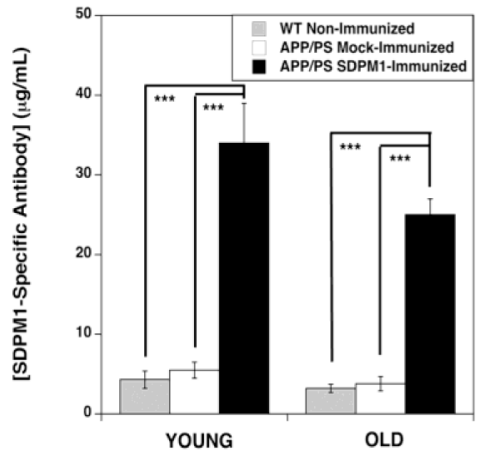

B

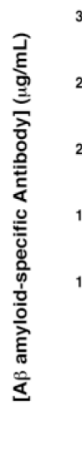

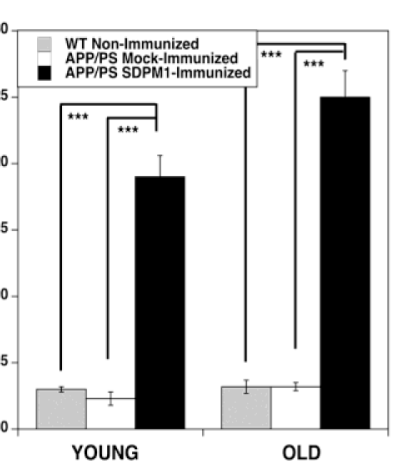

C

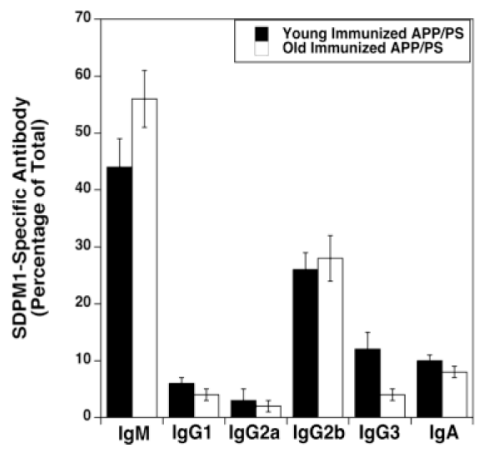

Figure 1. Immunization of YOUNG and OLD APPswePSEN1dE9 (APP/PS) mice with SDPM1 conjugated to ALUM

SDPM1-immunized mice were given four subcutaneous immunizations, one every two weeks, of $100 \mu \mathrm{g}$ SDPM1-4E peptide conjugated to ALUM. Mock-immunized APP/PS mice were similarly vaccinated with ALUM alone. Wild type (WT) mice were not immunized. YOUNG APP/PS mice were immunized beginning at 6 months of age, while OLD APP/PS mice were immunized beginning at 12 months of age. All mice were bled and serum antibody titers to SDPM1 (A) and A $\beta 1-42$ amyloid (B) assayed at 6 months after immunizations had begun. Relative amounts mouse SDPM1 antibody subtypes were also determined in SDPM1-immunized APP/PS animals (C). Errors are SEM for $n=10-12$ animals per condition, assayed in duplicate. 

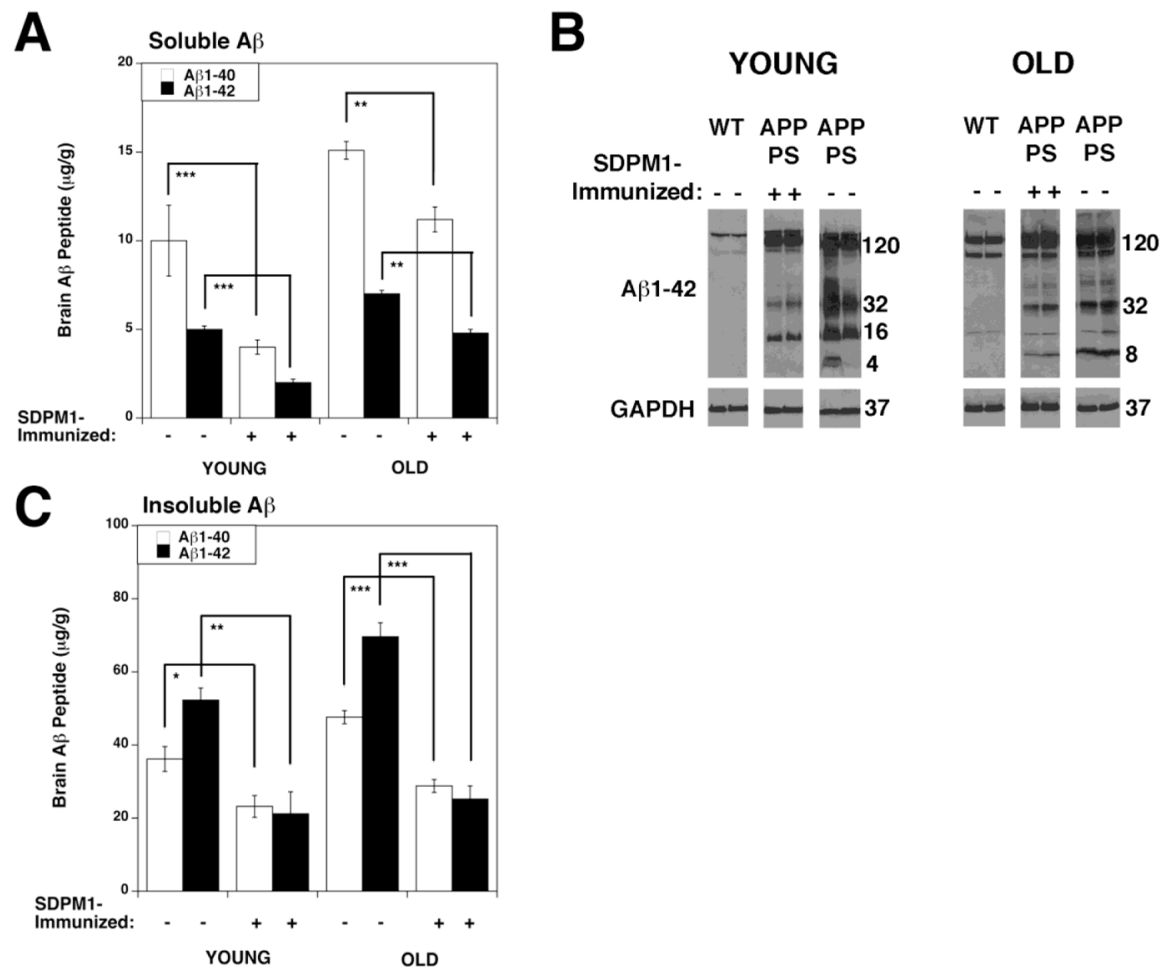

Figure 2. A $\beta 1-40$ and $A \beta 1-42$ brain peptide levels are reduced in SDPM1-immunized APP/PS mice

$A \beta 1-40$ and $A \beta 1-42$ peptide levels were measured in the SDS-soluble (A) and SDS-

insoluble (C) fractions of YOUNG and OLD mock-immunized and SDPM1-immunized APP/PS mice. Errors are SEM for $\mathrm{n}=10-12$ animals per condition, with measures assayed in duplicate. $* \mathrm{P}<0.05, * * \mathrm{P}<0.01, * * * \mathrm{P}<0.001$ (B) Low molecular weight, SDS-soluble, $\mathrm{A} \beta$ amyloid oligomers were separated on gradient Tris/Tricine gels and blotted with an antibody to A $\beta 1-42$ (6E10). Two samples per condition are shown. Blots were stripped and reprobed with antibody to GAPDH as a control for protein loading and transfer. 
A
SDPM1 Immunized
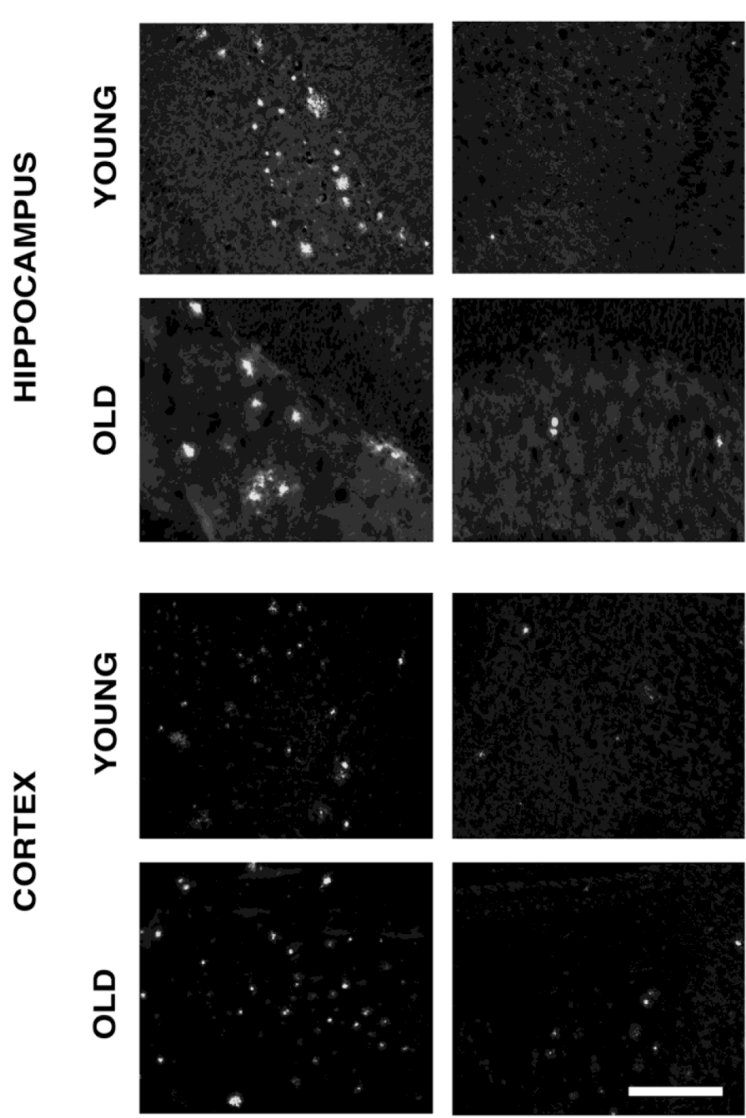

B
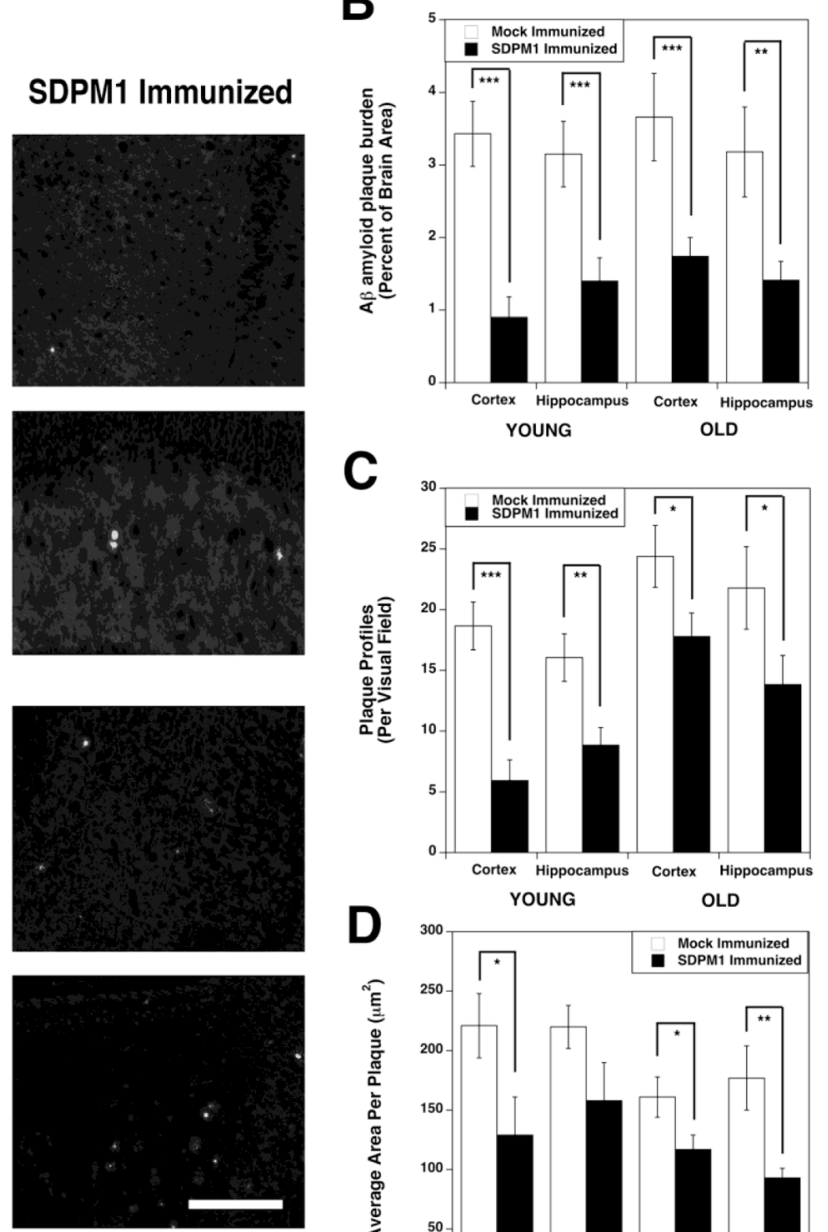

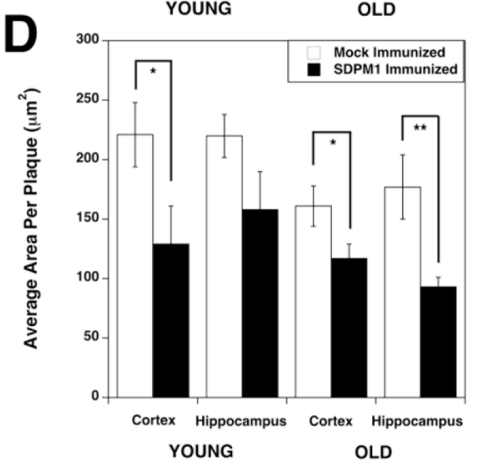

Figure 3. Reduced amyloid plaque burden in APP/PS mice immunized with SDPM1 Brains were serially sectioned and stained for dense core amyloid plaques with Thioflavin $S$ (A). Amyloid plaque burden (B), numbers of amyloid plaque profiles (C) and average amyloid plaque size (D) were quantified from sections of cortex and hippocampus. Errors are SEM for $\mathrm{n}-10-12$ animals per condition. Bar in $\mathrm{A}$ is $200 \mu \mathrm{m}$. ${ }^{*} \mathrm{P}<0.05,{ }^{*} * \mathrm{P}<0.01$, $* * * \mathrm{P}<0.001$ 
A

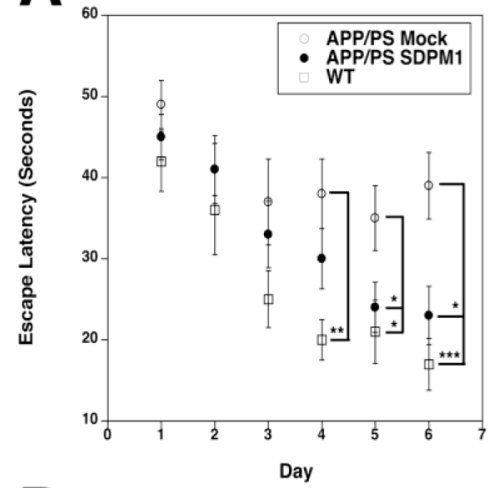

D

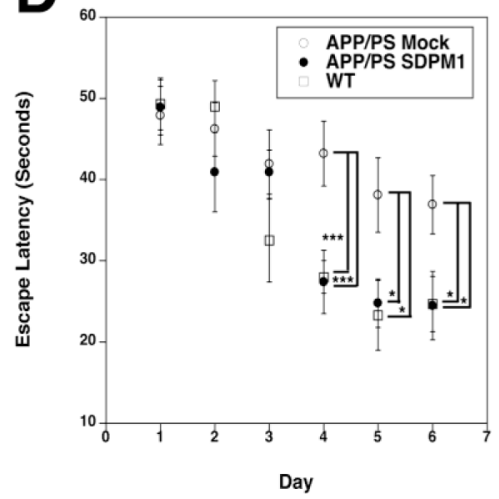

B

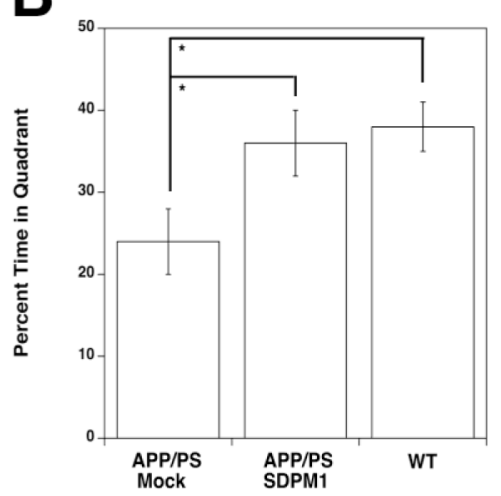

E
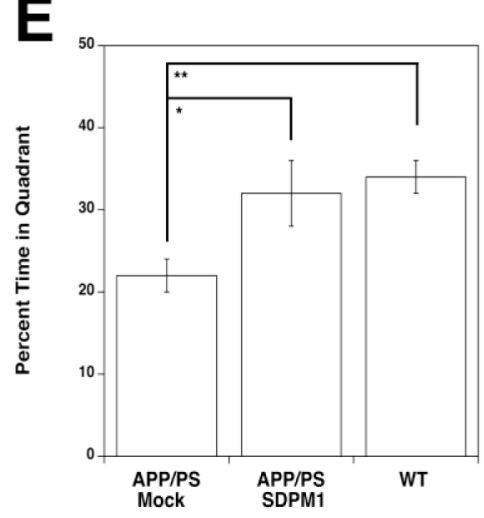
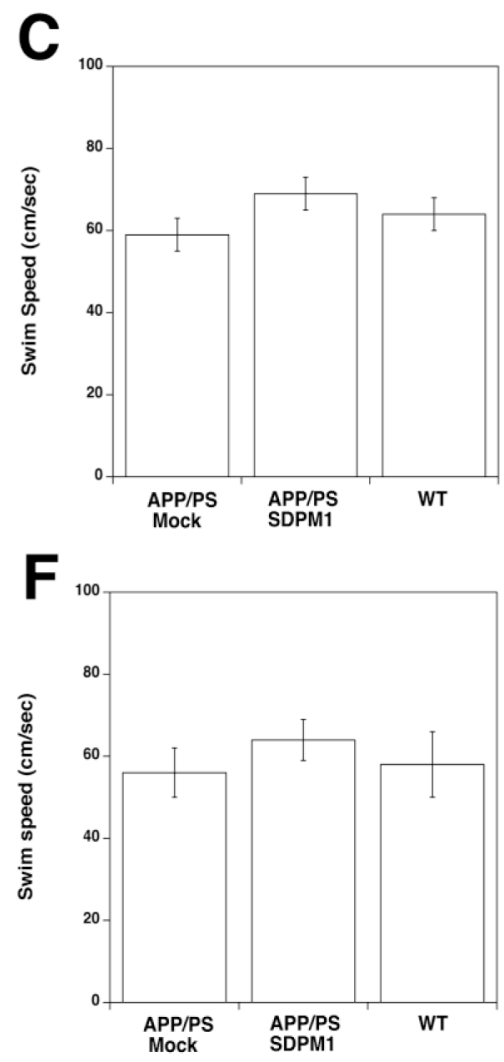

Figure 4. SDPM1 immunization improves learning and memory in YOUNG and OLD APP/PS mice

SDPM1-immunized YOUNG (A-C) and OLD (D-F) APP/PS mice showed improvement in Morris Water maze assays of learning (A, D) and memory (B, E). Mice were compared agematched mock-immunized APP/PS mice and non-immunized wild type (WT) mice. Overall swim speed was not significantly changed between any two groups in either experiment $(C$, F). Errors are SEM for $\mathrm{n}=10-12$ animals per condition. $* \mathrm{P}<0.05$, $* * \mathrm{P}<0.01, * * * \mathrm{P}<0.001$ 


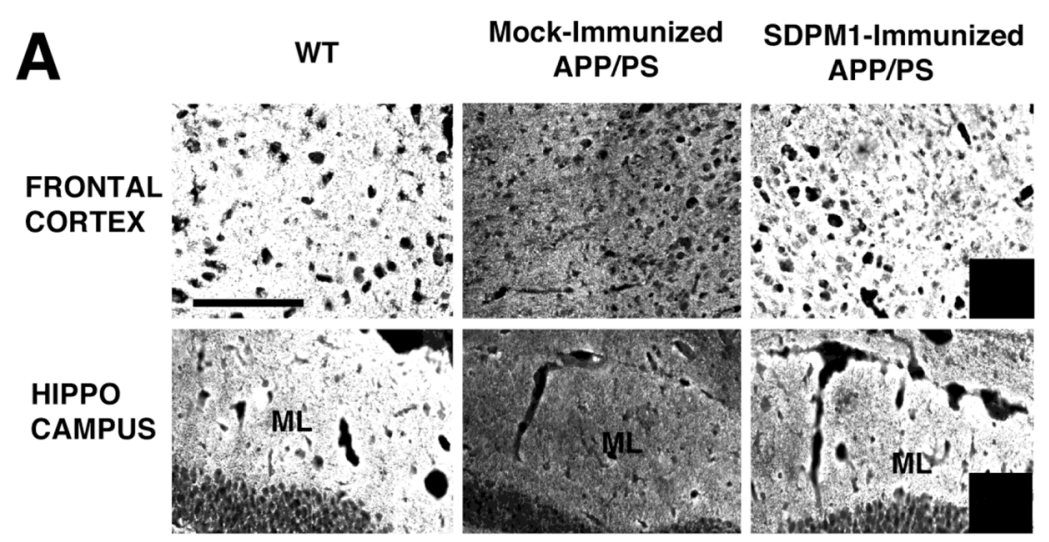

B
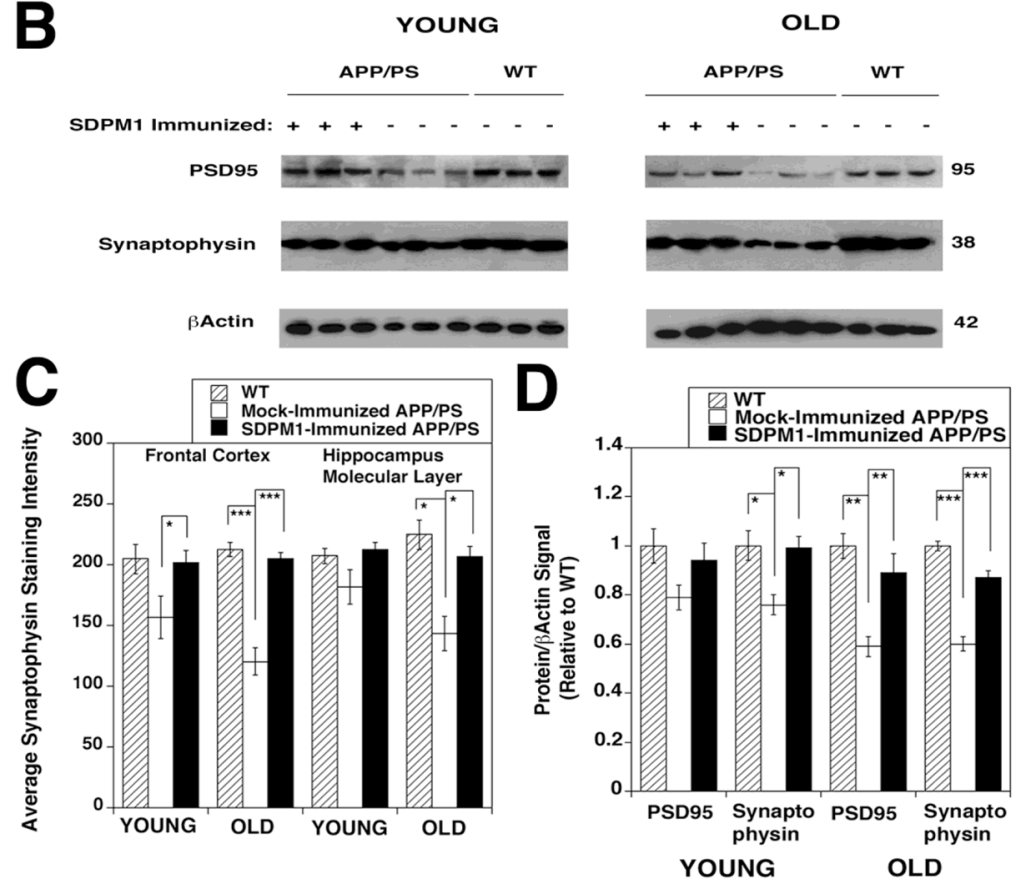

Figure 5. Increased expression of synaptic brain proteins after SDPM1 immunization of APP/PS mice

(A) Regions of the frontal cortex and the outer molecular layer of the hippocampus (ML) were imaged after staining of brain sections with an antibody to synaptophysin. OLD APP/ PS mice, either mock-immunized or SDPM1-immunized, were compared to age-matched wild type (WT) mice. Small inserts at the right show absence of signal with secondary antibody alone. Bar is $200 \mu \mathrm{m}$. (B) $20 \mu \mathrm{g}$ of purified brain plasma membranes were solubilized from SDPM1- or mock-immunized YOUNG and OLD APP/PS mice and nonimmunized wild type (WT) mice and separated on gradient SDS-PAGE gels. Brain lysates were immunoblotted for synaptophysin, PSD95 or $\beta$ Actin. Quantification of synaptophysin immunostaining (C) and PSD95 and synaptophysin immunoblotting (D) for age-matched wild type (WT), mock-immunized and SDPM1-immunized APP/PS mice. Errors are SEM for $\mathrm{n}=10-12$ animals per condition. $* \mathrm{P}<0.05, * * \mathrm{P}<0.01, * * * \mathrm{P}<0.001$ 


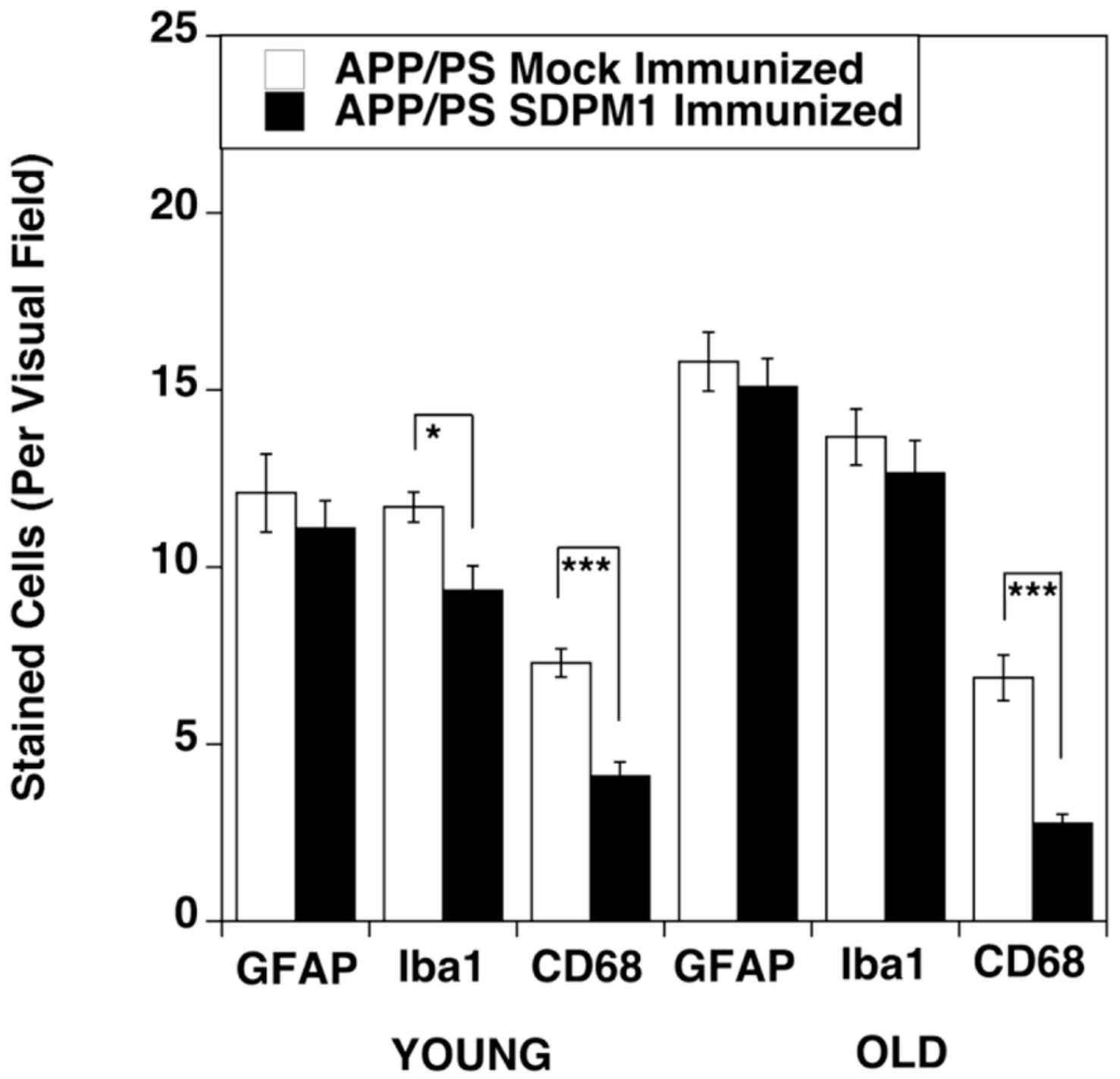

Figure 6. Absence of increased inflammatory cells in SDPM1-immunized APP/PS mouse brain Serial brain sections of cortex from YOUNG and OLD APP/PS mice, either mockimmunized or SDPM1-immunized, were analyzed for expression GFAP, Iba1 or CD68. Errors are SEM for $\mathrm{n}=10-12$ animals per condition. $* \mathrm{P}<0.05, * * \mathrm{P}<0.01$ 


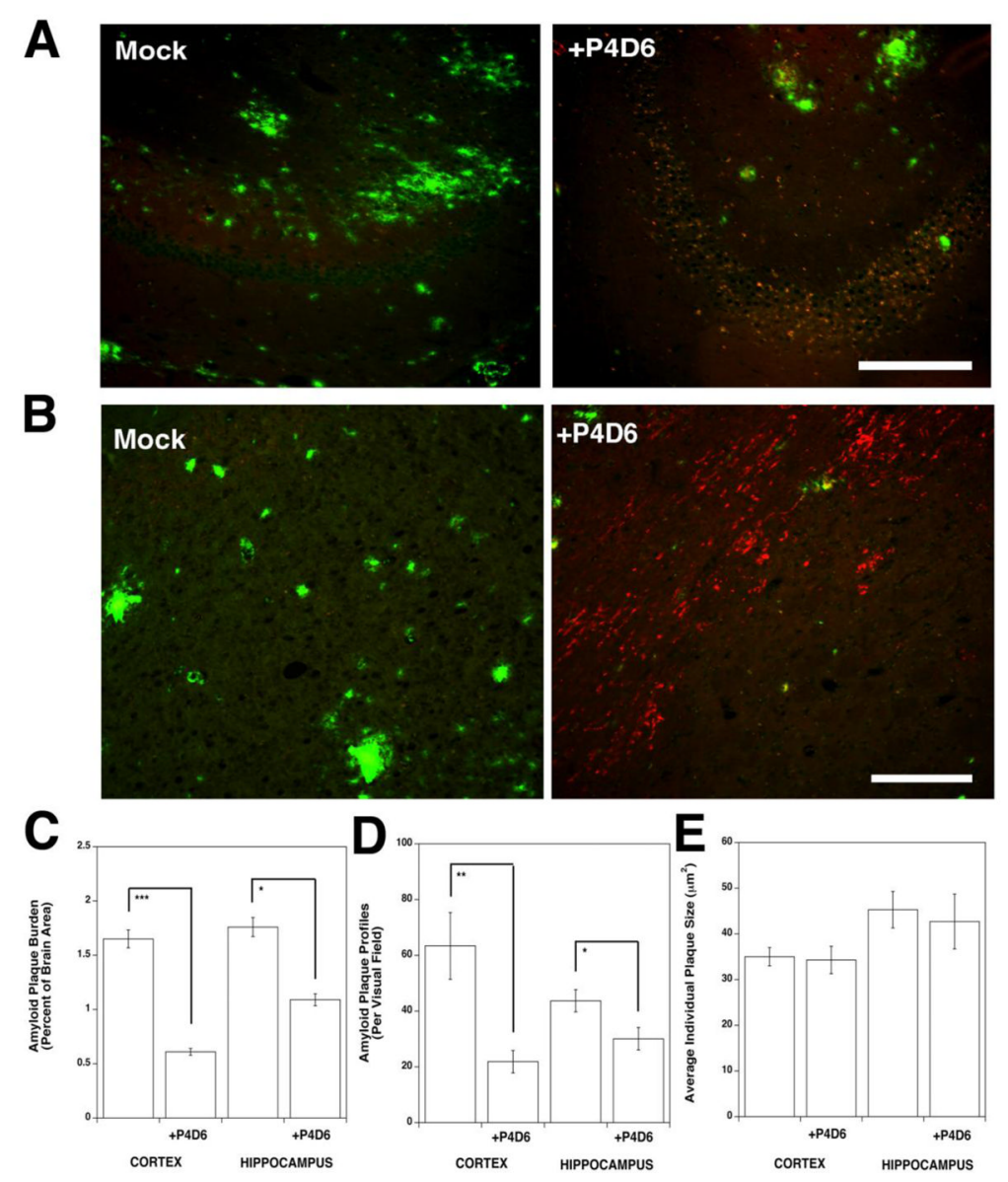

Figure 7. Intracerebral injection of P4D6 in cortex and hippocampus lowers amyloid plaque burden at two weeks post-injection in APP/PS brain

Brain sections of hippocampus (A) or cortex (B) were co-stained with anti-mouse IgMrhodamine, to visualize injected P4D6, and Thioflavin S, to visualize dense core amyloid plaques, fourteen days after intracerebral injection of P4D6 antibody in the cortex or hippocampus. Individual stains were imaged on an epifluorescence microscope using rhodamine (red)- or fluorescein (green)-specific filters. Merged red and green images are shown in all four panels, with overlap in yellow. Bar is $200 \mu \mathrm{m}$ in A and B. Quantification of amyloid plaque burden (C), amyloid plaque profiles (D) and average amyloid plaque size (E) 14 days after P4D6 injection versus control. Errors are SD for $n=4$ animals per condition. $* \mathrm{P}<0.05, * * \mathrm{P}<0.01, * * * \mathrm{P}<0.001$ 

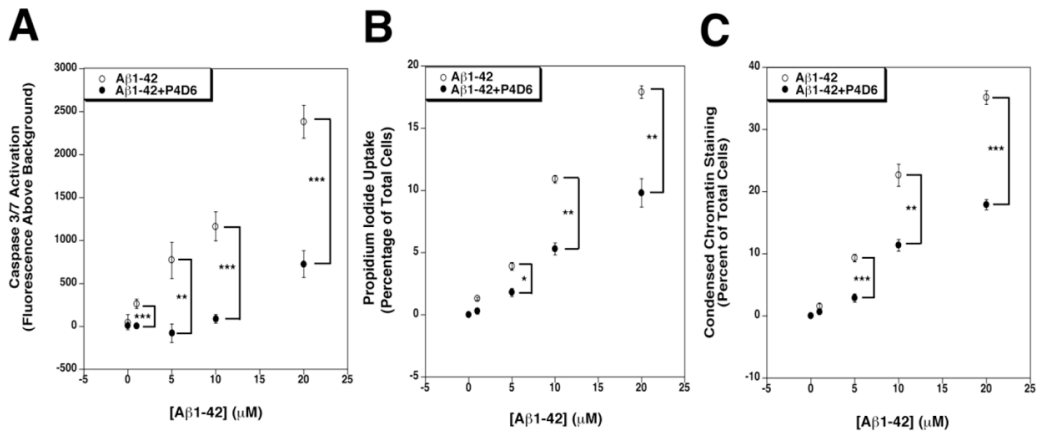

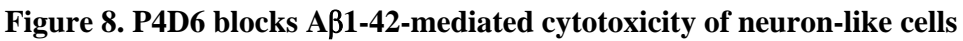

Retinoic acid differentiated SH-SY5Y cells were cultured in the presence of different concentrations of $A \beta 1-42$ amyloid or $A \beta 1-42$ amyloid that had been pre-incubated with (20:1 mol/mol) P4D6 antibody. Cells were assayed for activation of Caspase 3/7 (A), uptake of propidium iodide $(\mathrm{B})$ or condensed chromatin after staining with Hoechst dye $(\mathrm{C})$. Errors are SEM for $\mathrm{n}=10$ experiments per condition. $* \mathrm{P}<0.05$, $* * \mathrm{P}<0.01, * * * \mathrm{P}<0.001$ 


\section{A}

\begin{tabular}{|l|}
\hline CDWGKGGRWRLWPGASGKTEAC (SDPM1 peptide) \\
CPGRSPFTGKKLFNQEFSQDQC (Second SDPM1-like peptide) \\
\hline CKASGYTFTSYWMHWVKQRPGQGLEWIGYNPSTGYTEYNQKFKDKATL \\
TADKSSSTAYMQLSSLTSEDSAVYYC \\
(P4D6 Heavy chain variable region) \\
\hline CRSSTGAVTTSNYANWVQEKPDHLFTGLIGGTSNRAPGVPVRFSGSLIGDK \\
AALTITGAQTEDDAMYFC \\
(P4D6 Light chain variable region) \\
\hline
\end{tabular}

B

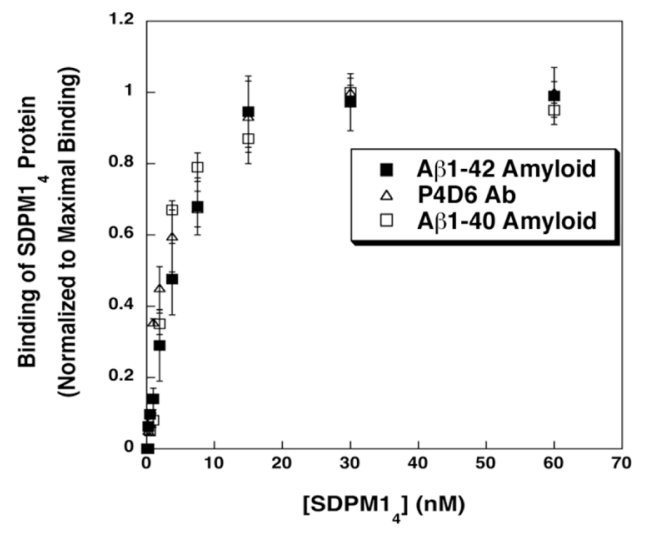

Figure 9. Identification of multiple SDPM1 peptide motifs in the P4D6 heavy chain variable domain and a role for SDPM1 multivalency in $A \beta$ amyloid binding

(A) Comparison of amino acids from the SDPM1 peptide (and a second SDPM1-like peptide) with the cysteine-bridged variable domain of the heavy and light chain of P4D6 show two SDPM1-like motifs within the P4D6 heavy chain sequence. Hydrophobic and basic amino acids are in bold, while SDPM1 motifs are underlined. (B) An epitope-tagged tetramer of the SDPM1 peptide $\left(\mathrm{SDPM}_{4}\right)$ was produced, purified and studied for binding to A $\beta 1-40$ or A $\beta 1-42$ amyloid and the P4D6 antibody (Ab). Errors are SEM for $n=6$ experiments per condition. 